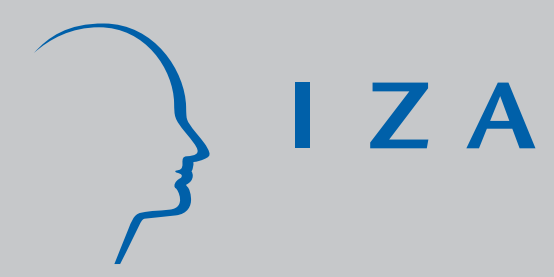

IZA DP No. 1813

Contractual Employment Protection and the Scarring Risk of Unemployment

Elke J. J ahn

Thomas Wagner

October 2005 


\title{
Contractual Employment Protection and the Scarring Risk of Unemployment
}

\author{
Elke J. Jahn \\ Institute for Employment Research (IAB), \\ University of Erlangen-Nuremberg and IZA Bonn \\ Thomas Wagner \\ University of Applied Sciences, Nuremberg
}

Discussion Paper No. 1813

October 2005

\author{
IZA \\ P.O. Box 7240 \\ 53072 Bonn \\ Germany \\ Phone: +49-228-3894-0 \\ Fax: +49-228-3894-180 \\ Email: iza@iza.org
}

\begin{abstract}
Any opinions expressed here are those of the author(s) and not those of the institute. Research disseminated by IZA may include views on policy, but the institute itself takes no institutional policy positions.
\end{abstract}

The Institute for the Study of Labor (IZA) in Bonn is a local and virtual international research center and a place of communication between science, politics and business. IZA is an independent nonprofit company supported by Deutsche Post World Net. The center is associated with the University of Bonn and offers a stimulating research environment through its research networks, research support, and visitors and doctoral programs. IZA engages in (i) original and internationally competitive research in all fields of labor economics, (ii) development of policy concepts, and (iii) dissemination of research results and concepts to the interested public.

IZA Discussion Papers often represent preliminary work and are circulated to encourage discussion. Citation of such a paper should account for its provisional character. A revised version may be available directly from the author. 


\section{ABSTRACT}

\section{Contractual Employment Protection and the Scarring Risk of Unemployment}

Risk-averse job seekers fearing the scarring effect of unemployment meet vacancies offering contractual employment protection (CEP) in form of guaranteed employment (GEC) or severance pay contracts (SPC). A GEC fully eliminates both the income risk and the scarring risk of unemployment. SPC diversify the income risk, but provide only limited protection against the scarring risk. (1) Workers strictly prefer contract market to spot market jobs. (2) A higher productivity, a lower probability of demand shocks or of finding a re-employment after a dismissal as well as lower public unemployment benefits increase the fraction of workers concluding a GEC. (3) Although firms are risk-neutral, first-best SPC are not incentive compatible under asymmetric information on the demand for the output of the job. In the second-best equilibrium, a positive fraction of over-insured workers will conclude a GEC, while workers signing a SPC incur income risk. (4) With asymmetric information on the reemployment status of a dismissed worker, employees who conclude a third-best SPC face both uninsurable income risk and the unemployment scar. Workers with a precautionary motive who expect a large or long lasting scar, conclude SPC with wage replacement rates strictly larger than one and low recession wages, which make their jobs more viable.

JEL Classification: J31, J32, J81

Keywords: scarring effect of unemployment, contractual employment protection, guaranteed employment contract, severance pay contract, implicit contract, moral hazard, prudence

Corresponding author:

Elke J. Jahn

Institute for Employment Research (IAB)

Regensburger Str. 104

90478 Nürnberg

Germany

Email: Elke.Jahn@iab.de

\footnotetext{
* We are grateful to Michael Burda and the participants of the Annual Congress 2005 of the Verein für Socialpolitik (VfS), Bonn, for their valuable and helpful comments.
} 


\section{Introduction}

There is growing evidence that unemployment not only causes the loss of income, but that it also inflicts a long-term 'scar' upon the displaced. The scarring effect of unemployment manifests itself through, for example, a loss of social status, social exclusion, a deterioration of the human capital and the personality of the displaced, an increased future incidence of unemployment and lower subsequent earnings. The paper presents a model in the spirit of the theory of implicit contracts about the impact of the income and the scarring risk of unemployment on the demand for contractual employment protection (CEP).

Whereas many OECD economies provide statutory employment protection, CEP seems to be a rare phenomenon. The public labor law or the public unemployment insurance may crowd out CEP, or, as has often been argued, information asymmetries may preclude any offer of the respective contract terms. However, it is difficult to judge the relevance of these conjectures, because there are only few investigations into the terms of labor contracts prevailing in the OECD member countries (Parsons 2002, Malcomson 1999).

Our model focuses on two forms of CEP. In addition to a guaranteed employment contract (GEC), workers may trade the scarring risk of unemployment for a higher wage and choose from a continuum of severance pay contracts (SPC). SPC vary with respect to the wage, the separation probability, the amount of severance pay and the supplemental unemployment benefits (SUB) paid by the employer in addition to the public unemployment compensation. We analyze the factors that determine the equilibrium shares of the labor force entering into a GEC or a SPC under different information structures.

The paper is organized as follows. Section II reviews the literature on employment protection. Section III addresses the question of how to integrate employment guarantees into labor economics. Section IV introduces the model with symmetric information and explores the properties of the first-best SPC and GEC. Section V presents two types of information asymmetries. First we assume that only the employers observe the product demand, which makes the separation decision non-contractible. Next we assume that the re-employment status of a dismissed worker is private information, such that the SUB become also non-contractible. Section VI summarizes the results, the Appendix provides proofs of the propositions.

\section{Literature}

Regulations and rules on employment protection may be classified into those imposed by the government and those that are the result of private or collective agreements. Statutory em- 
ployment protection is explicit and public knowledge, whereas private employment protection is often implicit and not easily observable by third parties. In line with the labor market policy in many countries (Holzmann et al. 2003, OECD 2004) the bulk of the literature analyses the effects of statutory employment protection, especially of firing taxes, compulsory severance payments and notice periods.

Firing taxes reduce the quasi-rent of a match, while severance payments prima facie redistribute the rent in favor of the worker. Alvarez and Veracierto (2001) follow Hopenhayn and Rogerson (1993) and model a labor market with compulsory severance payments, but allow for search frictions. In contrast to the findings of Hopenhayn and Rogerson, the calibrated version of their model shows that the severance payment increases aggregate employment and the welfare of the workers. The gains in welfare and employment are due to a reduction in search costs caused by the severance payment. Bertola (2004) presents a model with a firing tax. If the government uses the tax to finance the mobility costs of the dismissed workers, then both aggregate output and the welfare of the workers may rise. Gáldon-Sánchez and Güell (2003), Goerke (2002) and Fella (2000) integrate compulsory severance payments into the shirking model of Shapiro and Stiglitz (1984). Fella (2000) shows that the unemployment rate decreases and worker welfare increases, if the severance payment goes to the dismissed worker. In contrast to these findings, Gáldon-Sánchez and Güell (2003) argue that a compulsory settlement increases the unemployment rate, if third parties, such as a court in the case of a claim for wrongful dismissal, cannot easily distinguish between a dismissal for economic reasons and a dismissal due to misbehavior. Goerke (2002) compares compulsory settlements for individual and collective dismissals. In particular, settlements payable for collective dismissals may increase aggregate employment.

The macroeconomic theory of the 'natural rate of unemployment' examines the effect of a firing tax on employment and unemployment duration. As Ljungqvist (2002) argues, different specifications of the theory can lead to opposite effects of a given firing tax. For example, calibrated versions of the matching model of Mortensen and Pissarides (1994) imply that the firing tax reduces the natural rate (Mortensen und Pissarides 1999, Ljungqvist 2002). This result is at variance with the conclusions drawn by Hopenhayn and Rogerson (1993) for the case of a frictionless labor market, where the implementation of a firing tax in a Pareto-optimal general equilibrium lowers employment and the welfare of the workers.

Severance payments and notice periods are also negotiated in individual employment contracts and collective bargaining agreements. However, there is very little empirical evidence 
and not much economic theory on the extent and the importance of private CEP. The theoretical literature on the subject includes the contributions to the theory of implicit contracts (Azariadis 1975, Rosen 1985) by Grossman and Hart (1981, 1983), Kahn (1985) or Arnott et al. (1988). More recently, papers based on the theory of implicit contracts dealing with optimal employment agreements have been presented by Pissarides (2002), Parsons (2002) and Burguet and Caminal (2004). Pissarides (2002) analyzes a model with risk-averse workers, whose jobs are destroyed by shocks associated with shifts in tastes or technology. The efficient contract contains both a severance pay and a notice period prior to termination in addition to the wage. Burguet and Caminal (2004) present an overlapping generations model, in which young and old workers are risk-neutral with respect to the income volatility within a period. A bargained severance pay permits young workers to smooth their consumption between periods. The optimal employment contract, which determines the wages of the first and the second period of the life-cycle in addition to a severance pay, generates the optimal number of dismissals and fully smoothes the inter-temporal income stream of young workers. If the job productivity at the end of the first period is less than the endogenous reservation productivity, the worker will be dismissed. The bargained severance pay fully offsets the difference between the spot-market wage subsequently earned by the dismissed worker and the contract wage for the second period. If wages for the second period are non-contractible due to asymmetric information, the number of dismissals will be too high in equilibrium and private employment protection fails; a firing tax can correct this misallocation.

\section{Employment Guaranties}

None of the above papers deals with a type of widespread employment protection, namely the employment guarantee. Employment guarantees, 'Guaranteed employment contracts', 'guarantees of non-closure', 'location guarantees' etc. seem to be of great importance for public labor law as well as for collective and possibly individual labor agreements in many OECD countries, see Bryson et al. (2004) for the UK.

Why do employment guarantees exist? The model explores two answers, which focus first on uninsurable income risk and second on the diseconomies of a job displacement. On a labor market with technological or institutional search frictions, an employment guarantee may be the only means of a worker to protect himself against welfare losses due to uninsurable income risk or the scarring effect of unemployment.

Neoclassical labor economics presumes that workers demand insurance against the risk of unemployment, because they are averse to a volatile remuneration. In contrast to this well es- 
tablished but narrow theory, there is growing evidence that workers are not only averse to a volatile income, but that they also fear what is called in parts of the literature the scarring effect of unemployment (Clark and Oswald 1994, Winkelmann et al. 1998, Arulampalam et al. 2001a, b, Clark 2001, Clark et al. 2001, Di Tella et al. 2001, Frey and Stutzer 2002, Clark and Postel-Vinay 2005). A job loss is often associated with loss of social status, disintegration of the worker's family, deterioration of his human capital, a significant income loss in subsequent employment and even with negative intergenerational welfare effects (Ruhm 1991, Hansen and Imrohoroglu 1992, Jacobson et al. 1993, Arulampalam 2001a, b, Rogerson and Schindler 2002, Oreopoulos et al. 2005). The jobless must bear, moreover, the exclusion from those (in-)tangible 'community goods', which are available only to the members of a 'firm community'. Even though the exclusion from the firm community is hardly ever mentioned in labor economics, the protection against 'the arbitrary separation of the bonds to a firm community' (Deutscher Bundestag, 1951) was used by the German legislature in 1951 as the sole rationale for establishing the German Dismissal Protection Act. The above observations give reason for the assumption that, on a labor market with search frictions, the unemployment risk has at least two different dimensions, the income risk, which is the traditional focus of labor economics, and the scarring risk of unemployment.

How to model employment guarantees and how to integrate such guarantees into labor economics? The paper by Schmitz (2004) explores statutory employment guarantees and provides conditions under which this type of public employment protection does indeed increase efficiency. Parsons (2002), which we take as our starting point, analyzes a setting with contractual employment guarantees. The labor market offers the workers not only severance pay contracts (SPC) as in the reviewed literature on implicit or optimal labor agreements, but also guaranteed employment contracts (GEC). A first-best SPC frees a worker from income volatility, but it does not prevent termination. A GEC provides both an unconditional employment guarantee and a claim to a risk-free wage.

However, the attempt to include the GEC in labor economics encounters difficulties, because, workers do not obtain the GEC for free. In comparison to a SPC, workers entering into the GEC must accept a lower wage. The wage differential is compensation for the additional risk-costs associated with the GEC. Risk averse workers may accept the premium, if the GEC relieves them from otherwise uninsurable income risk. The reason why, for example, Akerlof and Miyazaki (1980) find that workers strictly prefer a GEC is that the implicit contract on which their argument is based is incomplete, so that workers without a GEC bear uninsurable 
income risk. Section V.C deals with the 'Wage Bill Argument'. However, with symmetric information and low transaction costs, the terms of a first-best SPC should be complete, that is, SPC should completely diversify the idiosyncratic part of a worker's income risk. Why would a worker ask then for a GEC? A worker covered by (private or public) unemployment insurance, which provides a wage replacement rate of $100 \%$ just like a first-best SPC, will not suffer a welfare loss (Hurd 1980), when the firm terminates his job and he experiences, for example, long-term unemployment due to search frictions. Quite to the contrary, the welfare of a LTU with a replacement rate of $100 \%$ will exceed that of his working colleagues, if leisure is a 'normal' good.

The difficulty consists thus of explaining why a worker, who could conclude a high wage contract with a complete coverage of his income risk, nonetheless prefers a low wage contract but with a supplemental employment guarantee. The resolution of the difficulty is provided by the insight that unemployment not only brings a loss of income, but also leaves a long lasting scar on the displaced (Layard 2005). SPC completely diversify the income risk, but offer only a partial protection against the scarring risk of unemployment, while a GEC eliminates both the income and the scarring risk of unemployment.

\section{The Model}

\section{A. Timing of Events}

Spot Market. There are two labor markets, a spot market and a contract market. A worker may search the spot market at any time during the period. If he opts for the spot market, he will find a job with probability $p$ and become unemployed otherwise. $y v$ is the spot market wage, where $y$ is the worker's productivity and $v$ is a parameter reflecting institutional or technological frictions. The unemployed receive public unemployment benefits $y b$ and suffer the idiosyncratic scarring effect $y \zeta \geq 0$, which is revealed at the end of the period. In the following, we assume for the 'replacement rates' $b$ and $v$ that

$$
0<b<v .
$$

Contract Market. In the contract market equilibrium, a worker can choose between two forms of CEP, see Fig. 1. The GEC specifies a wage $w_{B}$ and an enforceable employment guarantee, where we exclude the case of nonperformance by assumption. The terms of a SPC depend on the presumed information structure. With symmetric information, the equilibrium 
SPC defines, in addition to the wage $w_{A}$, a severance pay $A$ and SUB $B$, which are due, if a released worker cannot find a follow-up job and becomes unemployed. A separation rule completes the SPC. The rule specifies a reservation output $y R$ at which firm and worker separate, when the job is hit by an adverse demand shock and the demand falls below $y R$.
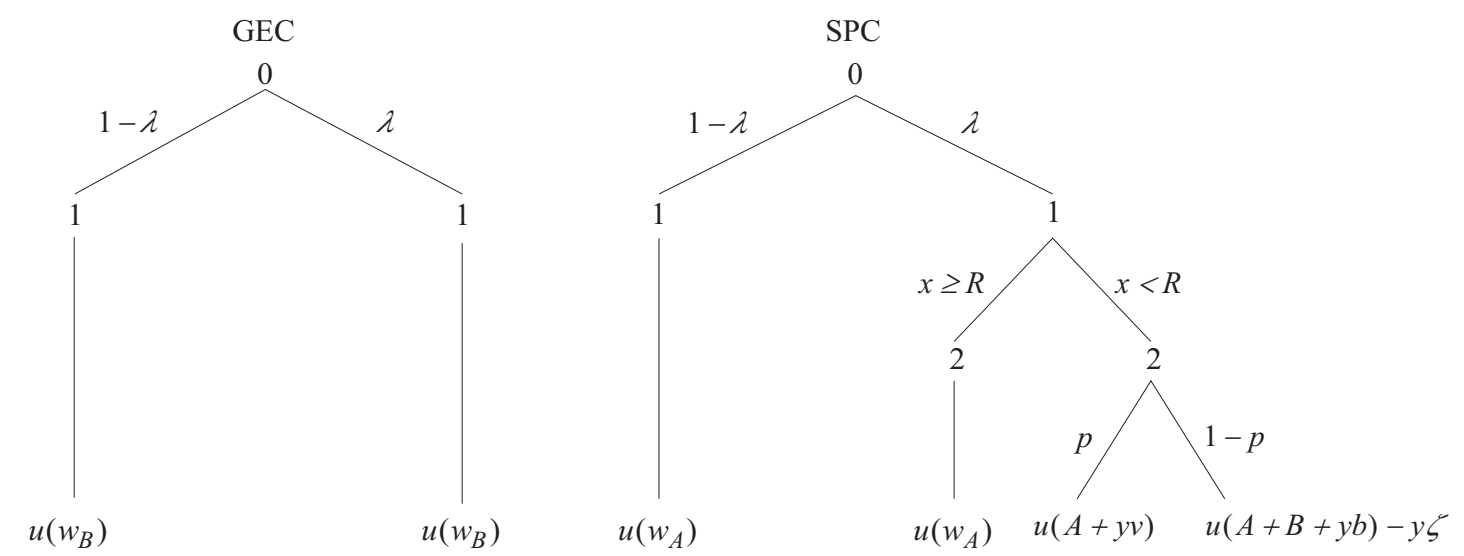

Fig. 1: Contract Market

Jobs with CEP are available only at the beginning of the period at stage 0 , at which contracts are concluded. With symmetric information, both parties of a contract observe whether the job is hit by a shock at stage 1 , an event which occurs with probability $\lambda$. Based on the observed demand and the availability of alternative market opportunities, the parties decide whether to execute or to modify the contract, which may be renegotiated by mutual consent. If they approve their agreement and the contract is a SPC, they decide whether to produce $(x \geq R)$ or to terminate the job $(x<R)$. At stage 2, a released worker looks on the spot market for reemployment. He fails to find a suitable job and becomes unemployed with probability $1-p$. An unemployed protected by a SPC receives the SUB $B$ from his former employer in addition to the public benefit $y b$. The equilibrium income of the unemployed with a SPC is thus equal to $A+B+y b$, while the earnings of a terminated job seeker, who did find a re-engagement, amount to $A+y v$.

\section{B. Profit and Utility Function}

Demand shock. $y>0$ is the output of a filled job in the good state. Idiosyncratic demand shocks arrive with probability $\lambda \in(0,1)$. The output of a job hit by a shock is $y x$, where $x$ is drawn from a general distribution $G$ with support $0 \leq \alpha \leq x \leq 1$. The shock $x$ has a probability density $g$ with $g(x)=G^{\prime}(x)>0$ for all $x \in[\alpha, 1]$, so that $\alpha<\mu<1$, where $\mu$ is the mean of the shock distribution. We assume throughout that $G$ is common knowledge. 
Contract. An employment contract $C=\left[w, C_{\lambda}\right]$ consists of the wage $w$, which is paid in the good state, and a real-valued function $C_{\lambda}:[\alpha, 1] \rightarrow \mathbf{R}^{4}$, which specifies the contract provisions in case of a demand recession. $C_{\lambda}(x)=[r(x), \omega(x), A(x), B(x)]$ are the contract terms conditional on the occurrence of the recession state $x \in[\alpha, 1]$. The indicator function $r$ specifies whether the job will produce $(r(x)=1)$ and the worker is paid the wage $\omega(x)$, or whether the job is closed down $(r(x)=0)$ and the worker receives the severance payment $A(x)$ and the option to claim $B(x)$, if he does not find a follow-up job and becomes unemployed.

Profit Function. In the good state, the profit of the firm is $y-w$. If the job is hit by a shock $x$ and the contract $C_{\lambda}(x)$ stipulates production, the profit is

$$
J^{+}\left(C_{\lambda}(x)\right)=y x-\omega(x)
$$

If $r(x)=0$, the contract stipulates separation and the profit is equal to the termination costs

$$
J^{-}\left(C_{\lambda}(x)\right)=-[A(x)+(1-p) B(x)]
$$

From (1) and (2), the profit of a job bound to the contract $C=\left[w, C_{\lambda}\right]$, if hit by a shock $x$, is $J\left(C_{\lambda}(x)\right)=r(x) J^{+}\left(C_{\lambda}(x)\right)+(1-r(x)) J^{-}\left(C_{\lambda}(x)\right)$, whereas the ex ante expected profit of the job, $J(C)$, is given by $J(C)=(1-\lambda)(y-w)+\lambda \mathrm{E}_{\mathrm{G}}\left[J\left(C_{\lambda}(x)\right)\right]$, where the expectation is taken with regard to the distribution $G$.

Utility Function. A worker owns one unit of time, during which he can produce up to $y$ units of the output. The worker is either employed or unemployed. If employed, his end-ofperiod utility from consuming $c$ is $u(c)$. If unemployed, his end-of-period utility is $v(c, y \zeta)$, where $y \zeta$ is the scarring effect of unemployment. The welfare loss due to the scar is increasing in the worker's human capital or productivity $y$. The utility functions fulfill the following assumption.

(A2) $u: \mathbf{R}_{+} \rightarrow \mathbf{R}$, the von-Neumann-Morgenstern utility function of the employed, is a $C^{2}$ function with $u^{\prime}>0$ and $u^{\prime \prime}<0$. The utility function of the unemployed, $v: \mathbf{R}_{+} \times \mathbf{R}_{+} \rightarrow \mathbf{R}$, is 'quasi-linear' with respect to the scarring effect of unemployment, $v(c, y \zeta)=u(c)-y \zeta$. The scar $\zeta \geq 0$ is a worker-specific random variable with distribution function $Z$ and mean $z=$ $\int_{0}^{\infty} \zeta d Z(\zeta) \geq 0$.

Workers are homogenous with respect to $y$, but may differ with respect to $z$. For worker types with a high value of $z$, their social and legal status as an employed citizen is very impor- 
tant for their wellbeing; in contrast, a neoclassical worker with $z=0$ ascribes no significance to such intangible factors.

If a worker signs a contract $C=\left[w, C_{\lambda}\right]$, his budget in the good state is $c=w$, and his utility is $u(w)$. If the job is hit by a shock, the utility depends on whether production or separation occurs. If $C_{\lambda}$ stipulates production in state $x$, the firm pays the contract wage $\omega(x)$ and the utility of the worker is

$$
U^{+}\left(C_{\lambda}(x)\right)=u(\omega(x))
$$

If $r(x)=0$, the job is closed down, and the terminated worker moves to the spot market to look for a re-employment. With probability $p$, he finds a job with wage $y v$. Together with the severance pay $A(x)$, his consumption is $c(x)=A(x)+y v$ and his utility $u(A(x)+y v)$. With probability $1-p$, he becomes unemployed. Being protected by the contract $C_{\lambda}$ which stipulates the severance pay $A(x)$ and the SUB $B(x)$, his consumption is $c(x)=A(x)+B(x)+y b$. Accounting for the scarring effect, his ex post utility is $u(A(x)+B(x)+y b)-y \zeta$. The demand shock, the transition to a follow-up job and the scar are independently distributed random events. Thus, the expected utility of a worker $z$, who is terminated in state $x$, is

$$
U^{-}\left(C_{\lambda}(x)\right)=p u(A(x)+y v)+(1-p)[u(A(x)+B(x)+y b)-y z] .
$$

From (3) and (4), the expected utility of a worker protected by a contract $C=\left[w, C_{\lambda}\right]$, whose job is hit by a shock $x$, is $U\left(C_{\lambda}(x)\right)=r(x) U^{+}\left(C_{\lambda}(x)\right)+(1-r(x)) U^{-}\left(C_{\lambda}(x)\right)$, while his ex ante expected utility is $U(C)=(1-\lambda) u(w)+\lambda \mathrm{E}_{\mathrm{G}}\left[U\left(C_{\lambda}(x)\right)\right]$.

Remark 1. Obviously, our naïve ' $\zeta$-theory' presupposes that the scarring effect is exogenous and resembles a non-actuarial and non-marketed negative consumption externality. The jobless compare their status with their self-perception or with the socio-economic status of a reference group and, as in the literature on the happiness research, suffer cet. par. a welfare loss equal to $y \zeta \geq 0$. The scarring effect could depend, for example, on the employment carrier of the worker, on his age and education, on the strength of his family ties, on the local unemployment rate or on social work norms (Clark and Oswald 1994, Stutzer and Lalive 2004). We take this heterogeneity into account by assuming different worker types earmarked by a type specific distribution of the scarring effect.

Remark 2. For convenience, we assume that the utility function of the jobless is linear in $y \zeta$, so that the 'scarring risk of unemployment' is not a literal risk in the sense of the neoclas- 
sical risk theory. Moreover, there is neither a market, where a worker could buy coverage against the scarring effect, nor a welfare state, which provides statuary employment protection; the only means to reduce the endogenous likelihood of the scarring effect are the provisions of the employment contract, which will be discussed in more detail in the following section.

\section{Efficient Labor Contracts}

Lagrangian function. An employment contract $C=\left[w, C_{\lambda}\right]$ is efficient with respect to a worker of type $z$, if $C$ maximizes the ex ante expected utility $U(C)$ of $z$ subject to the participation constraint of a non-negative ex ante expected profit $J(C) \geq 0$, where we assume for the time being that the reservation utility of the firm is equal to zero. $\mathcal{L}(C, \delta)=U(C)+\delta J(C)$ is the Lagrangian function of the maximization problem, and $\delta \geq 0$ is the Lagrange multiplier associated with the participation constraint. The Langrangian is a concave function of the contract terms with the following first-order conditions (FOC) for an interior solution

$$
\begin{gathered}
\frac{\partial \mathcal{L}}{\partial w}=(1-\lambda)\left[u^{\prime}(w)-\delta\right]=0 \\
\frac{\partial \mathcal{L}}{\partial \omega(x)}=\lambda r(x)\left[u^{\prime}(\omega(x))-\delta\right]=0 \\
\frac{\partial \mathcal{L}}{\partial A(x)}=\lambda(1-r(x))\left[p u^{\prime}(A(x)+y v)+(1-p) u^{\prime}(A(x)+B(x)+y b)-\delta\right]=0 \\
\frac{\partial \mathcal{L}}{\partial B(x)}=\lambda(1-r(x))(1-p)\left[u^{\prime}(A(x)+B(x)+y b)-\delta\right]=0 .
\end{gathered}
$$

Inspection of the FOC (5) - (8) yields the following results, where $y I_{S}$ with $I_{S}=p v+(1-p) b$ is the expected income of a worker without a contract, who searches for a spot market job.

LEMMA 1. (i) The Lagrange multiplier $\delta$ is equal to the marginal utility of consumption in the good state, such that in view of (A2) $u^{\prime}(w)=\delta>0$. (ii) If production occurs in a recession state $x$, then $r(x)=1$ and $u^{\prime}(\omega(x))=\delta$. (iii) If the job is closed down in a recession state $x$, then $r(x)=0$ and $u^{\prime}(A(x)+y v)=u^{\prime}(A(x)+B(x)+y b)=\delta$, such that

$$
w=\omega=A+(1-p) B+y I_{S}=A+y v=A+B+y b .
$$

Remark 3. An ex ante efficient employment contract fully shifts the consumption risk of the risk-averse worker to the risk-neutral firm. The contract wages $w$ and $\omega$, the severance pay $A$, and the SUB $B$ are all state independent, while the marginal utility of consumption is equal in all possible states, which in turn implies (9). The ex-ante and the ex-post wage replacement 
rates are equal to one. The ex ante expected replacement rate sets the expected income of a terminated worker, $A+(1-p) B+y I_{S}$, into relation to his contract wage. Likewise, the $e x$ post replacement rates set the income of a terminated worker who found a spot market job, $A+y v$, or who became unemployed, $A+B+y b$, into relation to his wage.

Remark 4. Obviously, the public unemployment compensation $y b$ crowds out the private SUB $B$ on a one-for-one basis, as the equations (9) imply $B=y(v-b)$.

Remark 5. Whereas $B>0$, in view of assumption (A1), the severance pay $A=w-y v$ can be negative, if the spot market wage exceeds the contract wage. To exclude negative severance payments, we could add a non-negativity constraint for $A$ to the maximization problem. But this constraint would make the characterization of the solution more tedious without adding new insights, except the one that a higher equilibrium share of workers will enter into a GEC, if an admissible contract must satisfy the condition $A \geq 0$.

Remark 6. As the FOC make clear, with an additive separable utility function for the jobless and, moreover, with jobless, whose preferences are neutral with respect to the volatility of the scarring effect, the terms of an efficient labor contract do not depend on the ex post welfare loss $y \zeta$. However, the ex ante expected welfare loss $y z$ operates through the indicator function and determines the efficient ex ante termination rule and in particular whether the efficient contract for a worker of type $z$ is a SPC or a GEC.

Reservation productivity. To establish the optimal ex ante termination rule, assume that $C=\left[w, C_{\lambda}\right]$ is an efficient contract for worker $z \geq 0$. Furthermore, assume that the job is hit by a shock $x \in[\alpha, 1]$. If production occurs, firm and worker earn the joint income $y x$. If firm and worker separate, their joint income is $y I_{S}$. Thus, $y h(x)$, with $h(x)=x-I_{S}$, is the differential rent between the joint income from continuing and from closing the job down. For the continuation rent $h(x)$, we assume

$$
h(\alpha)<0<h(1)
$$

As $h(x)$ is a strictly increasing $C^{1}$ function on $[\alpha, 1]$, considering (A3), there is a unique productivity $R_{m}$ with $\alpha<R_{m}<1$ for which $h\left(R_{m}\right)=0$. Next, let the wage and the replacement payments of $C$ be given. Then, considering (A3), the following lemma applies.

LEMMA 2. (i) The worker $z \geq 0$ favors production to separation for all $x \in[\alpha, 1]$, the preference being strict, if $z>0$. (ii) The employer of $z$ prefers production in all states $x \geq R_{m}$ and strictly prefers separation, if $x<R_{m}$. (iii) Therefore, regardless of the worker type $z \geq 0$, 
$r(x)=1$ holds, whenever $x \geq R_{m}$. (iv) For all worker types $z \geq 0$, there is a unique reservation productivity $R(z)$ depending on $z$, with $\alpha \leq R(z) \leq R_{m}$, such that $r(x)=1 \Leftrightarrow x \geq R(z)$.

Profit and utility function. Due to the reservation property and equations (9), the terms of an efficient employment contract $C(z)$ for a worker $z \geq 0$ are uniquely determined by the contract wage $w$ and the reservation productivity $R$, which are both functions of $z$. Consequently, we obtain the ex ante expected utility of $z$ from

$$
\begin{aligned}
U(w, R) & =(1-\lambda) u(w)+\lambda \int_{\alpha}^{R} U^{-}\left(C_{\lambda}\right) d G(x)+\lambda \int_{R}^{1} U^{+}\left(C_{\lambda}\right) d G(x), \\
& =u(w)-\lambda G(R)(1-p) y z
\end{aligned}
$$

where $\lambda G(R)$ is the separation probability, while $\lambda G(R)(1-p)$ is the endogenous likelihood that the contract is terminated and the redundant worker suffers the scarring effect. Correspondingly, the ex ante expected profit of the job bound to the contract $C(z)$ is

$$
\begin{aligned}
J(w, R) & =(1-\lambda)(y-w)+\lambda \int_{\alpha}^{R} J^{-}\left(C_{\lambda}\right) d G(x)+\lambda \int_{R}^{1} J^{+}\left(C_{\lambda}(x)\right) d G(x), \\
& =E y(R)-l(w, R)
\end{aligned}
$$

where $E y(R)$ is the ex ante expected revenue with $E y(R)=y[(1-\lambda)+\lambda \mu(R))]$ and $\mu(R)=$ $\int_{R}^{1} x d G(x)$, and $l(w, R)$ are the ex ante expected labor costs associated with $C(z)$. Labor costs consist of wage and termination costs: $l=(1-\lambda G(R)) w+\lambda G(R)[A+(1-p) B]$. Considering (9), we can rewrite the termination costs to get: $l=w-\lambda G(R) y I_{S} \equiv l(w, R)$. Both the revenue and the labor costs are strictly decreasing functions of $R$, as $E y(R)^{\prime}=-\lambda g(R) y R<0$ and $l_{R}(w, R)=-\lambda g(R) y I_{S}<0$, where $l_{R}(w, R)$ denotes the partial derivative of the labor cost function with respect to $R$. Considering (A3), the marginal revenue is strictly larger than the marginal labor costs for all $R \in\left[\alpha, R_{m}\right)$, thus the marginal profit from an incremental rise of $R$ is strictly larger than zero: $J_{R}(R)=-\lambda g(R) y h(R)>0$.

Solution. To solve the model with respect to $w$ and $R$ for a given $z$, we need two equations. The first key equation is the participation constraint of the maximization problem, from which we get the implicit 'market price of the scarring risk' (MPS). The second equation results from the equality of the MPS and the willingness of worker $z$ to trade the scarring risk for a higher wage. 


\section{The Market Price of the Scarring Risk}

To illustrate the argument, we assume that labor contracts are implemented through a system of competitive product and labor markets with free entry. Firms and workers have symmetric information; the former supply jobs subject to the terms of an employment contract; job seekers, who observe all contract terms, conclude an agreement that maximizes their expected utility; free entry and competition ensure that only efficient labor contracts are viable.

The Market Price of the Scarring Risk. The ex ante expected profit of a competitive job is equal to zero, as is confirmed by Lemma 1 (i). From $J(w, R)=0$ and (11) follows the wage function $w:[\alpha, 1] \rightarrow \mathbf{R}$, which gives the wage $w(R)$, at which an active job offering a labor contract with reservation productivity $R$ earns zero expected profits

$$
w(R)=E y(R)+\lambda G(R) y I_{S} .
$$

The wage (12) is equal to the sum of the expected revenue and the ex ante expected market income of a dismissed worker. Fig. 2 shows the contract market curve (CMC), as we will call the graph of the wage function $(12)$, in the $(w, R)$-plane. In order to characterize the shape of the $\mathrm{CMC}$, we compute the first derivative of (12) with respect to $R$ to obtain

$$
w^{\prime}(R)=-\lambda g(R) y h(R)=M P S .
$$

It follows from (A3) and (13) that the $\mathrm{CMC}$ is strictly increasing on $\left[\alpha, R_{m}\right)$ and has a unique maximum at $R_{m}$. The set of efficient employment protection contracts for workers of type $z \geq 0$ corresponds to the increasing branch of the CMC, which encompasses two different forms of contracts. Severance pay contracts $C_{A}=\left[w_{A}, R\right]$ with $R \in\left(\alpha, R_{m}\right]$ and $w_{A}=$ $w(R)$ provide full coverage against the income risk, but only partial protection against the scarring risk, whereas the risk-free GEC $C_{B}=\left[w_{B}, \alpha\right]$ with $R=\alpha$ and $w_{B}=w(\alpha)$ fully shifts the income and the scarring risk to the firm. For workers of any type $z \geq 0$ a labor contract $C$ with reservation productivity $R \in\left(R_{m}, 1\right]$ and wage $w(R)$ is inefficient, as $C$ is dominated by more efficient contracts with wages at least as high as $w(R)$ and reservation productivities strictly lower than $R$.

With an increasing $R$, the likelihood of becoming jobless and suffering the unemployment scar grows. In equilibrium, the market offers the workers a compensation for accepting that risk, because an incremental increase of $R \in\left[\alpha, R_{m}\right)$ leads to a marginal profit equal to $J_{R}(R)>0$. We call the premium $M P S$, which the market is prepared to pay for the risk, the implicit market price of the scarring risk. Clearly, $M P S \leq J_{R}(R)$. Free entry and bidding up drive $M P S$ 
until all profit opportunities are exhausted and $M P S=J_{R}(R)$. Consequently, as $w^{\prime}(R)=$ $J_{R}(R)$, the slope of the $\mathrm{CMC}$ at $R \in\left[\alpha, R_{m}\right]$ reflects the equilibrium price of the scarring risk at the reservation productivity $R$. Note that the wage function (12) is strictly concave in the neighborhood of $R_{m}$. Fig. 2 represents a case where the CMC is strictly concave everywhere on $\left[\alpha, R_{m}\right)$, so that the risk premium MPS is strictly decreasing on $\left[\alpha, R_{m}\right)$ and approaches zero as $R$ converges to $R_{m}$ (see Appendix A2).

The willingness to accept the scarring risk. If a positive measure of workers of type $z \geq 0$ apply for work, the market will offer CEP with terms that maximize the expected utility of $z$. The contract terms preferred by $z$ can be derived by means of the tangential condition MPS $=$ $M R S$, where $M R S$ is the compensation expected by $z$ for accepting the scarring risk. We determine MRS using the total differential of the utility function (10). The marginal utility of income is $\partial U / \partial w=u^{\prime}(w)>0$, while the marginal disutility of the reservation productivity is $\partial U / \partial R=-\lambda g(R)(1-p) y z<0$ for $z>0$. The premium expected by $z$ for a higher separation probability is thus given by the marginal rate of substitution between the wage rate and the reservation productivity

$$
M R S \equiv \frac{d w}{d R}=-\frac{\partial U(z) / \partial R}{\partial U(z) / \partial w}=\frac{\lambda g(R)(1-p) y z}{u^{\prime}(w)} \geq 0 .
$$

The indifference curves of type $z$ increase thus monotonically, as represented in Fig. 2 for the worker types $z_{1}$ and $z_{2}$. Moreover, the depicted curves are strictly convex (see App. A3). Workers request a higher premium for a higher exposure to the scarring risk. Uniformly distributed demand shocks are sufficient for both the strict concavity of the CMC as well as the strict convexity of the indifference curves (see App. A2 and A3).

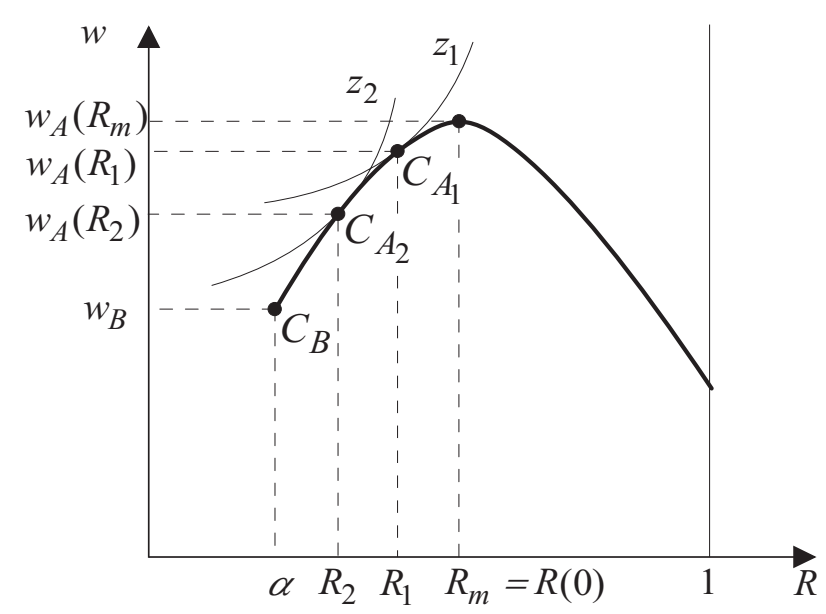

Fig. 2: Severance Pay Contracts of workers $z_{1}$ and $z_{2}$ 


\section{E. Contractual Employment Protection}

Self selection and wage dispersion. Next we address the question how the terms of an efficient labor contract depend on the expected scarring effect $z$. In equilibrium, workers of type $z_{1}$ and $z_{2}$ will choose those SPC $C_{A}(z)=\left[w_{A}(z), R(z)\right]$ with $w_{A}(z)=w(R(z))$ that satisfy the type-specific tangential condition, see Fig. 2, where $z_{1}<z_{2}$, as the lemma below will prove. Let $z \geq 0$ be a worker, who would conclude a SPC $C_{A}(z)$ in contract market equilibrium.

LEMMA 3. The reservation productivity of $C_{A}(z), R(z) \in\left(\alpha, R_{m}\right]$, is a strictly decreasing $C^{1}$ function of $z$ with $R(0)=R_{m}$. Thus, the greater $z$, the lower are the separation probability $\lambda G(R(z))$ and the contract wage $w_{A}(z)$ of $C_{A}(z)$. Therefore, the equilibrium is characterized by wage dispersion, which reflects the heterogeneity of the expected scarring effects.

The marginal worker type. Some workers prefer a risk-free GEC that eliminates not only the income, but also the scarring risk of unemployment. The GEC wage is $w_{B} \equiv w(\alpha)=y[1-$ $\lambda(1-\mu)]$ and the separation probability is $\lambda G(\alpha)=0$. Thus, the probability of becoming jobless, when protected by the GEC is $\lambda G(\alpha)(1-p)=0$. We will characterize next the marginal worker $z_{B}$, who is indifferent between the GEC and the type-specific SPC.

Proposition 1. The $z$-value of the marginal worker type, $z_{B}$, is determined by

$$
z_{B}=-h(\alpha) \frac{u^{\prime}\left(w_{B}\right)}{1-p}>0
$$

All workers with an ex ante expected scarring effect that exceeds $z_{B}$ prefer the risk-free GEC, whereas all others prefer to trade the scarring risk for a higher wage and demand a SPC with a positive exposure to the scarring risk of unemployment, see Fig. 3.

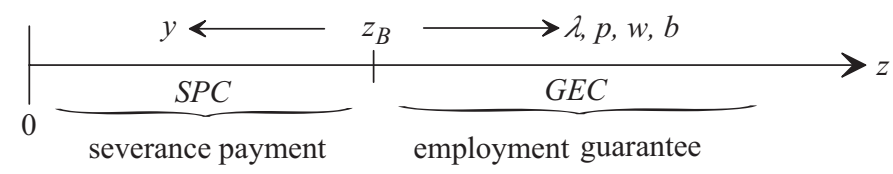

Fig. 3: Share of Workers Concluding a SPC or the GEC

Contract market versus spot market jobs. At stage 0 , see Fig. 1, worker $z \geq 0$ must decide between searching for a spot market or for a contract market job. The expected utility of a spot market job, $V(z)$, follows from $V(A, B, z)=p u(A+y v)+(1-p)[u(A+B+y b)-y z]$ with 
$V(z) \equiv V(0,0, z)$, because spot market jobs do not offer replacement payments. Nevertheless, the advantage of a spot market job can be a higher income. The ex ante expected spot market income of $z$ is $y I_{S}$, whereas with the efficient contract $C(z)=[w(z), R(z)]$, a SPC or a GEC, $z$ would earn $I_{C}(z)=(1-\lambda G(R(z))) w(z)+\lambda G(R(z)) y I_{S}$. Thus $y I_{S} \geq I_{C}(z)$ if and only if $y I_{S} \geq$ $w(z)$. Indeed, if the probability of a demand shock $\lambda$ is sufficiently high, then worker types exist, whose equilibrium contract wage is strictly lower than their spot market income $y I_{S}$.

LEMMA 4. Let $\lambda(1-\mu)>h(1)$. Then, a worker type $\hat{z} \in\left(0, z_{B}\right)$ with a contract wage $w_{A}(\hat{z})$ exists, for which $w_{A}(\hat{z})=y I_{S}$. For all worker types $z>\hat{z}$, the contract wage $w(z)$ is strictly lower than the spot market income $y I_{S}$, that is $w_{B} \leq w(z)<y I_{S}$.

On the other hand, the spot market has an obvious disadvantage inasmuch as workers are confronted with an exogenous probability of unemployment $1-p>0$, which might be too high at the given spot market wage in comparison to the transition probability $\lambda G(R(z))(1-p) \geq 0$ that $z$ would enjoy with $C(z)$. And indeed, workers of all types strictly prefer CEP to a spot market job. To prove this proposition, let $U(C(z))$ denote the expected utility of $z$, if $z$ concludes the efficient contract $C(z)$.

Proposition 2. For all worker types $z \geq 0$, the participation constraint for the contract market is satisfied as a strict inequality, i.e., $U(C(z))>V(z)$.

Comparative statics. The results of the comparative static analysis of the GEC, the SPC, and the $z$-value $z_{B}$ of the marginal worker type are summarized in the following lemma.

LEMMA 5. (i) (Productivity) An incremental increase of the worker's productivity will raise the wages of the GEC and the SPC and the corresponding severance pay, while the reservation productivities and the z-value of the marginal worker will fall. (ii) (Demand Shock) A higher probability of a demand shock will decrease the wages of the GEC and the SPC and the corresponding severance pay, while the $\mathrm{z}$-value of the marginal worker will rise. (iii) (Frictions) A change of the friction parameters has no influence on the GEC wage, while an increase of $p, v$ or $b$ will increase the SPC wages and the z-value of the marginal worker type. Moreover, the proportion of workers demanding the risk-free GEC tends towards zero, as $p$ approaches one. (iv) (Scarring effect) A raise of the expected scarring effect $z \geq z_{B}$ has no influence on the GEC wage, while an incremental raise of $z \in\left[0, z_{B}\right)$ will reduce the wage, the reservation productivity and the severance pay of the corresponding SPC. 


\section{F. Re-contracting}

Are the ex ante agreed upon separation rules of a SPC and the GEC ex post efficient? To explore this question, we first adhere to the assumption of no ex post competition. Next we assume that the firm observes an alternative use for the job endowment with an expected profit equal to $\Pi$ at stage 1 , see Fig. 1 . Contracts concluded at stage 0 can be renegotiated by mutual consent at stage 1 , after the demand state $x \in[\alpha, 1]$ and the profit $\Pi$ of the alternative market opportunity have been revealed to the contracting parties.

With regard to the separation rule of a contract $C(z)$, there are two cases to distinguish depending on the demand state $x$. The first occurs, when $x \geq R(z)$ and $\pi(x, z)<0$ apply, where $\pi(x, z)=y x-w(z)$ is the ex post profit of the firm. $C(z)$, which can be either a GEC or a SPC, stipulates production, although the firm would incur a loss. The firm, which strictly prefers separation, would like to renegotiate the termination rule of $C(z)$. In the second case, a recession state $x<R(z)$ occurs, such that the contract $C(z)$, which of course must be a SPC, stipulates separation. The worker $z$, who ex ante traded the scarring risk for a higher wage, would be exposed to the threat of the unemployment scar, if firm and worker would separate in accordance with $C(z)$. Although $C(z)$ fully covers the consumption risk, the worker nevertheless strictly prefers to modify $C(z)$ to 'save his workplace' if and only if $z>0$.

First assume that $x \geq R(z)$ and that the firm would incur a loss $\pi(x, z)<0$, if the worker refuses to re-contract. The employer prefers termination to production and would be prone to offer an ex post redundancy pay $a$ to get the worker's approval to renegotiate $C(z)$. If $z$ would be better off with the redundancy pay $a$ than with abiding to $C(z)$, which gives him a claim to his job and the wage $w(z)$, closing the job down would be ex post efficient. Of course, $a$ cannot exceed the loss to be avoided, so that $a$ must satisfy $a \leq \bar{a}(x, z) \equiv-\pi(z, x)$, where $\bar{a}(x, z)$ is the redundancy pay that would leave the employer of $z$ indifferent between continuing and terminating the job in the recession state $x$. As the worker protected by the contract $C(z)$ is guaranteed utility $u(w(z))$, a redundancy payment $a$ that would induce him to accept the separation proposal must satisfy $a \geq \underline{a}(z)$, where $\underline{a}(z)$ with $V(\underline{a}(z), 0, z)=u(w(z))$ is the state independent redundancy pay that would leave the worker just indifferent between continuing and terminating the job. Proposition 3 below will confirm that even the maximal separation rent $a(z)$, for which $a(z)=\arg \max \{\bar{a}(x, z)-\underline{a}(z): x \geq R(z)\}$, is negative, so that there exists indeed no redundancy pay $a$ acceptable to both the firm and the worker $z$. 
Next assume $x<R(z)$. In this case, the contract $C(z)$ must be a SPC stipulating separation. The neoclassical worker with $z=0$ being protected by $C(0)$, which gives him a claim to a flat consumption stream, would be indifferent between employment and unemployment and, furthermore, between a spot market job and his present workplace. Therefore, the neoclassical worker would quit in accordance with $C(0)$ without sustaining any welfare loss. In contrast, all other worker types cet. par. strictly prefer to save their workplace to a termination of their job. To avoid the unemployment scar, they even are willing to offer to the firm a wage cut. The wage $\underline{w}(z)$ that would leave $z$ indifferent between separation and continuation follows from $u(\underline{w}(z))=u(w(z))-(1-p) y z$, because, if production would not occur, the worker could claim the replacement payments guaranteed by $C(z)$ for which the equations (9) apply. The maximal wage cut a worker of type $z$ would tolerate, $\bar{\chi}(z)$, is therefore given by $\bar{\chi}(z)=$ $w(z)-\underline{w}(z)$. Except for the neoclassical worker for whom $\bar{\chi}(0)=0$, the wage cut is strictly positive for all $z>0$.

The minimal wage concession on which the employer of $z$ would insist to continue the job, $\underline{\chi}(x, z)$, can be determined as follows. As long as the renegotiated wage is lower than $\bar{w}(x, z)$, the firm would gain or at least not lose from continuing the job, where $\bar{w}(x, z)=y x+A(z)+(1-p) B$ is the wage that would leave the employer of $z$ indifferent between continuing and terminating the job in a recession state $x<R(z)$. Therefore, the minimal wage cut on which the employer of $z$ would insist during a renegotiation of $C(z)$ is given by $\underline{\chi}(x, z)=w(z)-\bar{w}(x, z)$. Clearly $\underline{\chi}(x, z)=-y h(x)$, so that $\underline{\chi}(x, z)$ is strictly decreasing in $x$, but does not depend on the worker type $z$, so we may write $\underline{\chi}(x)=\underline{\chi}(x, z)$ for all $z \geq 0$. Moreover, the minimal wage concession the employer would ask for is strictly greater than zero for all recession states $x<R(z)$. The following proposition actually confirms that $\underline{\chi}(R(z))>\bar{\chi}(z)$, where $\underline{\chi}(R(z))=\inf \{\underline{\chi}(x)$ :

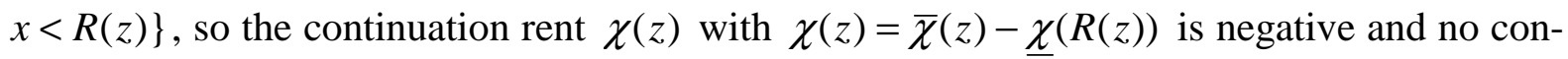
tinuation wage acceptable to both employer and employee exists.

Proposition 3. Without ex post competition, the separation rule of $C(z)$ is ex post efficient, i.e. neither the good state $(x=1)$ nor the recession states $x \geq R(z)$ yield a positive separation rent. Likewise in the recession states $x<R(z)$ there is no continuation rent to reap.

Let the parties observe ex post an alternative market opportunity for the firm, the expected profit of which is equal to $\Pi$, and define the following threshold values $\underline{\pi}(x, z) \equiv \bar{w}(x, z)-\underline{w}(z)<0$ 
and $\bar{\pi}(x, z) \equiv \underline{a}(z)-\bar{a}(x, z)>0$. There are two cases to distinguish. In the first, $x \geq R(z)$ and $\Pi>\pi(x, z)$ hold, such that $C(z)$ stipulates production, although the employer of $z$ strictly prefers separation. Obviously, the redundancy pay which the firm is ready to offer can not be higher than $\Pi+\bar{a}(x, z)$. Consequently, the decision to separate in a recession $x \geq R(z)$ is efficient if and only if $\Pi+\bar{a}(x, z)>\underline{a}(z)$ or, equivalently, if and only if $\Pi>\bar{\pi}(x, z)>0$.

Suppose next that $x<R(z)$. Then, $C(z)$ must be a SPC which stipulates separation. In this case, all but the neoclassical worker would be willing to accept a pay cut to save their job and avoid the unemployment scar. But to reach an agreement about the continuation of the job, the parties must be able to earn a rent. The maximal pay cut that would leave the worker indifferent between separation and continuation is still $\bar{\chi}(z)$, the minimal pay cut the employer would demand considering his market alternative is $\chi(x)+\Pi$, so the continuation would be efficient if and only if $\bar{\chi}(z)>\underline{\chi}(x)+\Pi$ or, rearranging terms, if and only if $\Pi<\underline{\pi}(x, z)<0$.

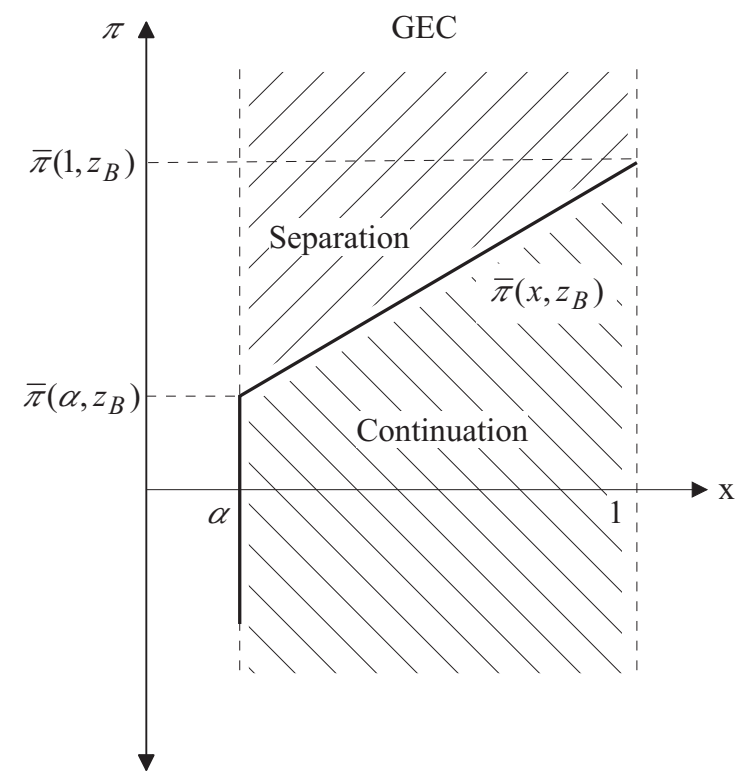

Fig. 4: Region of separation and continuation with a GEC

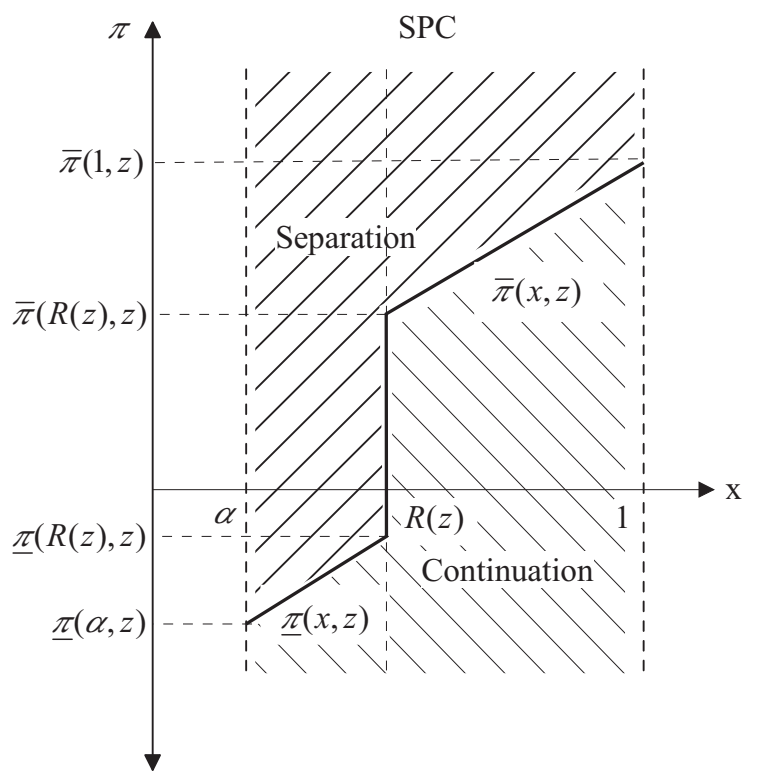

Fig. 5: Region of separation and continuation with a SPC

We can summarize the results as follows. First, if the expected profit of the market alternative $\Pi$ is high enough, such that $\Pi>\bar{\pi}(x, z)$, see Fig. 4 for the case of the GEC and Fig. 5 for the SPC, separation is efficient as parties can reap a separation rent. The firm would have to compensate the worker with a redundancy pay, if $x \geq R(z)$. Second, if $x<R(z)$ and $\Pi<\underline{\pi}(x, z)$, see Fig. 5, both worker and firm must fear a welfare loss from enacting $C(z)$, which stipulates separation. Continuation is efficient as parties could reap a continuation rent, whereby the worker would have to compensate the firm offering the employer a reduction of his contract wage. 


\section{Moral Hazard}

Although asymmetric information is usually mentioned as the main reason why CEP is rarely observed in practice, there seems to be neither theory nor empirical evidence to confirm this widely held opinion. The models in this section follow the traditional theory of implicit contracts with a focus first on the case of asymmetric information on the demand for the output of the firm. In the second part, we introduce in addition asymmetric information on the reemployment status of a dismissed worker. The section makes clear that there is a variety of asymmetric information structures that will induce job seekers to look for even stricter CEP than in the first-best equilibrium. Moreover, the second-best SPC use a two-wage structure, one wage for the good and another wage for the recession states. Of course, firms offer contracts with a completely rigid wage. But, under asymmetric information on the demand, the recession wage a worker prefers to contract, is strictly lower than the wage for the good state. The reason is that as a consequence of the information asymmetry the separation decision is no longer contractible and workers make use of the recession wage and the severance pay to induce their employer to implement the preferred separation probability, thereby sacrificing the income insurance function of a rigid wage. In contrast, if the re-employment status of a dismissed worker is private information, workers who sign a third-best SPC must bear income risk. Therefore, it can occur that all worker types want to conclude a GEC, as in the famous 'Wage Bill Argument' of Akerlof and Miyazaki (1980).

\section{A. Output Demand}

First, we assume that the workers or the court, in the case of legal proceedings, cannot verify the demand for the output of a job. There are two cases to distinguish, depending on whether the information asymmetry relates to the demand shock per se or, more specifically, to the observability of the ex post demand $y x$. We assume that a worker at stage 1 can verify whether his job is hit by a shock, but that he cannot observe the ex post demand state $y x$. Therefore, a SPC can be conditioned on whether the job is hit by a shock, but not on $y x$.

Given this information structure, a SPC $C_{A}=\left[w_{A}, \omega_{A}, A, B\right]$ has four components, namely the contract wages $w_{A}$ and $\omega_{A}$, which the worker is paid, respectively, in the good state and in a recession, the severance pay $A$ and the SUB $B$. As the contract cannot be conditioned on the demand state $y x$, the reservation productivity is not contractible and the firm unilaterally determines separation. The firm will terminate the job and dismiss the worker as soon as the operating loss $\omega_{A}-y x$ equals the expected costs of a dismissal $A+(1-p) B$. Thus the firm 
terminates the SPC, if $x<R$, where $R$ is determined by the incentive compatibility constraint $I C\left(C_{A}, R\right) \equiv A+(1-p) B-\left(\omega_{A}-y R\right)=0$.

The expected profit of a job with a SPC $C_{A}=\left[w_{A}, \omega_{A}, A, B\right]$ and the reservation productivity $R$ is

$$
J\left(C_{A}, R\right)=E y(R)-(1-\lambda) w_{A}-\lambda\left[(1-G(R)) \omega_{A}+G(R)[A+(1-p) B]\right]
$$

whereas the expected utility of a worker $z$ protected by $C_{A}$, whose employer picks the reservation productivity $R$, is

$$
U\left(C_{A}, R\right)=(1-\lambda) u\left(w_{A}\right)+\lambda(1-G(R)) u\left(\omega_{A}\right)+\lambda G(R) V(A, B, z) .
$$

Taking into account the free entry condition, the equilibrium SPC for a worker of type $z \geq 0$ corresponds to the solution of the following constrained maximization problem

$$
\max _{\left\{C_{A}, R\right\}} U\left(C_{A}, R\right) \quad \text { subject to } \quad J\left(C_{A}, R\right) \geq 0 \text { and } I C\left(C_{A}, R\right)=0 .
$$

Grossman and Hart (1981, 1983) emphasize that the first-best SPC between a neoclassical worker with $z=0$ and a risk-neutral firm is incentive compatible, even though the termination decision is not contractible. A risk-neutral firm making a contract with a neoclassical worker has no incentive to report a false demand state, because the revenue of the firm is at least as high as the labor cost savings from a dismissal in all demand states. The authors thus model the consequences of the information asymmetry under the assumption that the firm is risk-averse. In our model, the firm, although risk-neutral, has a strong incentive in a recession to announce a wrong demand state to terminate the job. The reason is that an optimal SPC not only fully insures the worker against the income risk, but also provides protection against the scarring risk, if $z>0$. Protecting a worker $z>0$ against the scarring risk forces the firm to hoard his labor in all recession states $x$, for which $R(z) \leq x<R_{m}$. If the output demand is private information, the firm can save labor hoarding costs and terminate the contract unilaterally at the profit maximizing $R$.

LEMMA 6. The first-best SPC of a worker of type $z \in\left(0, z_{B}\right)$ is not incentive compatible, if the demand for the output of the job is observed by the firm, but not by the worker.

$\mathcal{L}\left(C_{A}, R, \delta, \gamma\right)=U\left(C_{A}, R\right)+\delta J\left(C_{A}, R\right)+\gamma C\left(C_{A}, R\right)$, the Lagrangian of the maximization problem (18), is a concave function of the terms of the SPC and the reservation productivity. The FOC for an interior solution with $\delta \geq 0$ and $\gamma$ as the Lagrange multipliers of, respectively, the participation constraint and the incentive constraint are 


$$
\begin{gathered}
\frac{\partial \mathcal{L}}{\partial w_{A}}=(1-\lambda)\left[u^{\prime}\left(w_{A}\right)-\delta\right]=0 \\
\frac{\partial \mathcal{L}}{\partial \omega_{A}}=\lambda(1-G(R))\left[u^{\prime}\left(\omega_{A}\right)-\delta\right]-\gamma=0 \\
\frac{\partial \mathcal{L}}{\partial A}=\lambda G(R)\left[p u^{\prime}(A+y v)+(1-p) u^{\prime}(A+B+y b)-\delta\right]+\gamma=0 \\
\frac{\partial \mathcal{L}}{\partial B}=\lambda G(R)(1-p)\left[u^{\prime}(A+B+y b)-\delta\right]+(1-p) \gamma=0 \\
\frac{\partial \mathcal{L}}{\partial R}=-\lambda g(R)\left[u\left(\omega_{A}\right)-p u(A+y v)-(1-p)[u(A+B+y b)-y z]+\right. \\
\delta\left[A+(1-p) B-\left(\omega_{A}-y R\right)\right]+\gamma y=0
\end{gathered}
$$

Inspection of the FOC (19) - (23) yields the following results for the second-best SPC.

LEMMA 7. (i) The multiplier $\delta$ is equal to the marginal utility of consumption in the good state, $u^{\prime}\left(w_{A}\right)=\delta>0$. (ii) The multiplier $\gamma$, which reflects the difference between the marginal utility of consumption in the good and in the bad states, $\gamma=\lambda(1-G(R))\left[u^{\prime}\left(\omega_{A}\right)-u^{\prime}\left(w_{A}\right)\right]$, is nonnegative, $\gamma \geq 0$. The firm pays $\omega_{A}$ in a recession and $w_{A}$ in the good state, where $\gamma>0$ and thus $w_{A}>\omega_{A}$ if and only if $z>0$. (iii) As $A+y v=A+B+y b$, a second-best SPC fully shifts the income risk of the dismissed worker to the firm. (iv) Nonetheless, in contrast to the neoclassical worker, workers of type $z>0$ do not fully insure their income risk. Rather, $z$ prefers a state independent ex post replacement rate which is strictly larger than one, $A+y v=$ $A+B+y b>w_{A}>\omega_{A}$. (v) The second-best reservation productivity $R(z) \in\left[\alpha, R_{m}\right]$ is a decreasing function of $z$ with $R(0)=R_{m}$.

Remark 7. Dismissed workers of type $z>0$ receive a severance payment $A$, for which $A+y v>w_{A}>\omega_{A}$, as Lemma 7 (iv) indicates. This contrasts with the second-best result of Grossman and Hart (1981) for a contract between a neoclassical worker and a risk-averse firm, for which $A+y v<\omega_{A}$. Moreover, while the equilibrium unemployment is greater in the second-best than in the first-best situation in Grossman and Hart (1981), the scarring risk together with the asymmetric information about labor's marginal product causes unemployment to be lower in the second-best equilibrium of the contract market, as follows from Proposition 1 and Lemma 7 (v) together with Proposition 4 below, which characterizes the second-best marginal worker type. Of course, the 'over-employment' in the contract market equilibrium can be one reason for 'mass unemployment' in the overall economy.

Remark 8. The hypotheses that a risk-averse worker in a job-specific recession is paid a wage that is strictly less than the wage he would have earned in the good state, i.e. $\omega_{A}<w_{A}$, is confirmed by the empirical literature on the phenomenon of unemployment scarring (Greg- 
ory and Jukes 2001). The reason for this two-wage structure of a second-best SPC is the prevailing information asymmetry and not the demand recession per se. As the separation decision is not contractible, workers with $z>0$ use the recession wage and the severance pay to induce the employer to pick the preferred reservation productivity. Considering the incentive constraint, a lower recession wage and/or a higher severance pay will cet. par. induce the firm to implement a lower separation probability.

As the distribution function $G$ and its support is public knowledge, the fact that the separation decision is not contractible is of no importance for the terms of the risk-free GEC $C_{B}=$ $\left[w_{B}, \alpha\right]$. The fraction of workers that favors the risk-free GEC is larger in the second-best than in the first-best equilibrium. To prove this proposition, we first characterize the marginal worker type $z_{B_{2}}$, who is indifferent between the GEC and the type-specific second-best SPC. The marginal worker $z_{B_{2}}$ would sign a SPC with wages $w_{A}=\omega_{A}=w_{B}$. To induce the employer to choose the reservation productivity $R=\alpha$, the severance pay $A$ and the SUB $B$ must satisfy $A+y v=\omega_{A}-y h(\alpha)$ and $B=y(v-b)$. Given these terms of the type-specific SPC, the employer of the marginal worker will indeed choose $R=\alpha$ moreover, the participation constraint of the maximization problem (18) holds as a strict equality under these contract terms. In view of $\gamma=\lambda(1-G(R))\left[u^{\prime}\left(\omega_{A}\right)-u^{\prime}\left(w_{A}\right)\right]=0$ and Lemma 7 (iii), the FOC (23) implies the following equation for the marginal worker type

$$
z_{B_{2}}=\frac{u\left(w_{B}-y h(\alpha)\right)-u\left(w_{B}\right)}{(1-p) y}
$$

Proposition 4. The fraction of workers, who conclude the risk-free GEC, is strictly larger in the second-best than in the first-best contract market equilibrium, i.e. $0<z_{B_{2}}<z_{B_{1}}$, where $z_{B_{1}}$ is given by (15).

\section{B. Efficiency}

The second-best allocation of the income risk and the scarring risk is not efficient under the above information structure. There are two sources for the inefficiency. First, as Lemma 7 (iv) indicates, workers concluding a second-best SPC are under-insured, as they bear income risk. Second, all workers of type $z \in\left[z_{B_{2}}, z_{B_{1}}\right)$ are over-insured. They conclude the GEC, although their first-best alternative would be a SPC with a positive exposure to the scarring risk. 
To correct the market failure, a social planner subject to the same information asymmetry as the workers employs three instruments for each type $z \in\left(0, z_{B_{1}}\right)$, one to smooth consumption, a second to induce efficient separations and a third to regulate the market entry of the jobs.

To reallocate the income risk of the worker $z \in\left(0, z_{B_{1}}\right)$, the planner makes use of a wage transfer $t$. In case of a demand shock, the employer must pay the worker an amount $t$ in addition to the contract wage, if production takes place. Thus, the disposable income of the worker in a recession is $\omega_{A}+t$, if production occurs. Given a positive measure of workers of type $z$ and a corresponding number of competing employers, who take these workers on, we may assume that in view of the 'thick market' the contracting parties will behave as price takers with respect to the policy variable $t$. Let $w_{A}$ and $\omega_{A}$ be the contract wages that solve the maximization problem (18). Then the planner will choose $t$ to smooth the income of the worker such that $\omega_{A}+t=w_{A}$. But $\omega_{A}+t=w_{A}$ implies that the Lagrange multiplier $\gamma$ is zero, such that the disposable income of the worker in all possible states is equal and state independent, $w_{A}=$ $\omega_{A}+t=A+y v=A+B+y b$ from the FOC (19) - (22). The type-dependent wage subsidy $t$, therefore, is sufficient to shift the total income risk to the firm.

To induce the firm to realize the first-best separation decision, the planner makes use of a type-dependent firing tax $F$. The tax paid on separation is not a compensation transferred to the worker, it is a dismissal cost borne by the firm. The profit maximizing reservation productivity $R$, which the employer will implement given $F, t$ and the terms of the SPC, follows from the incentive constraint $A+(1-p) B+F-\left(\omega_{A}+t-y R\right)=0$. Inserting the terms of the firstbest contract into this equation gives $F=-y h(R)>0$, such that $d F / d z=-y d R / d z>0$.

Considering the payments $t$ and $F$ and inserting the above insurance equations (9) into the profit equation (17) gives the expected profit of a job bound to a SPC

$$
J\left(C_{A}, R\right)=E y(R)-\left[w_{A}-\lambda G(R) y I_{S}\right]-\lambda G(R) F+T .
$$

$T$ is a type-dependent subsidy that is used by the planner to reimburse the firing tax and to assure that the efficient number of jobs will be supplied in market equilibrium. For this to occur, it is necessary and sufficient that the equilibrium $R$ fulfills the wage function (12) and the tangential condition. Equation (25) and $J\left(C_{A}, R\right)=0$ imply

$$
w_{A}(R)=E y(R)+\lambda G(R) y I_{S}-\lambda G(R) F+T .
$$

Thus, given the subsidy $T(R)=\lambda G(R) F$, the wage equations (12) and (26) are equivalent and the market price of the scarring risk is determined by equation (13). 


\section{Re-employment Status}

The feasibility of a contract claim offering SUB depends on whether the former employer is able to observe the subsequent employment status of the dismissed worker. In view of the threat $z>0$, firms can be sure that workers have a strong 'intrinsic' motive to search for (re-) employment. But, if the result of the job search is unobservable, a dismissed worker would report in any case that he was unable to find a new job and would insist on his claim to $B$.

Given that neither the separation decision nor the SUB are contractible, severance pay contracts $C_{A}=\left[w_{A}, \omega_{A}, A\right]$ include a wage for the good state, a wage for the recession states and the severance pay. Agreements with a state independent completely rigid wage are, of course, not excluded from the set of admissible contracts. The third-best SPC for a worker of type $z \geq 0$ is determined by the solution to the maximization problem (18) with FOC (19) - (21) and (23), where we must set $B=0$ throughout. Below we first present some general results for the third-best SPC. Next we characterize the marginal worker type, who is indifferent between the GEC and the type-specific SPC. Finally we discuss two variants of SPC.

Let $C_{A}$ be a third-best SPC, and let $R$ be the incentive compatible reservation productivity associated with $C_{A}$. The FOC (19) - (21) and (23) yield the following general results for $C_{A}$ and $R$.

LEMMA 8. (i) The multiplier $\delta$ is equal to the marginal utility of consumption in the good state, $u^{\prime}\left(w_{A}\right)=\delta>0$. (ii) The ex post replacement rate of a dismissed worker who found a spot market job is strictly larger than one, $A+y v>\max \left\{w_{A}, \omega_{A}\right\}$. (iii) Workers self-select with respect to the expected scarring effect, such that the equilibrium reservation productivity $R(z)$ is a strictly decreasing function of $z$.

Marginal worker type. Without SUB, the fraction of over-insured workers preferring the risk-free GEC to a SPC increases further, as the next proposition for the marginal worker type $z_{B_{3}}$ of the third-best contract market equilibrium will prove. The marginal worker is indifferent between the GEC and the type-specific SPC, given that a solution of (18) for some $z>0$ with a reservation productivity $R(z) \in\left(\alpha, R_{m}\right]$ exists. The reason for the qualification is that one cannot exclude that, unlike the first-best and second-best situation, all worker types with $z \geq 0$ strictly prefer the risk-free GEC in the third-best contract market equilibrium to a SPC, i.e., it may be that $z_{B_{3}}=0$.

Proposition 5. If neither the SUB nor the separation decision are contractible, then $0 \leq z_{B_{3}}<z_{B_{2}}<z_{B_{1}}$, where $b \geq \alpha$ is sufficient for $z_{B_{3}}>0$. 
Remark 9. The 'Wage Bill Argument' of Akerlof and Miyazaki (1980) deals with the case $z_{B_{3}}=0$. Indeed, if $z_{B_{3}}=0$, the contract market equilibrium is a 'fixed-wage-cum-full- employment equilibrium', as the authors call this state of the labor market, where the 'fixed wage' is equal to the GEC wage $w_{B}$.

If $z_{B_{3}}>0$, there must be worker types $z \in\left[0, z_{B_{3}}\right)$ who strictly prefer a third-best SPC to the GEC, even though they are confronted not only with the scarring risk but also with uninsurable income risk. To explore the structure of the third-best SPC in more detail, we distinguish between two motives that shape the terms of a SPC, namely the precautionary motive and the wish to avoid the unemployment scar. Due to the precautionary motive, workers sign a SPC with an ex ante replacement rate strictly larger than one. The unemployment scar on the other hand is responsible for the worker's selection of the contract wages for the good and the recession states. If the expected scar is small, the prospect of a high replacement income dominates the decision. The worker favors separation to continuation at stage 1 and signs a SPC with $\omega_{A}>w_{A}$ to boost the separation probability. In the second, more realistic case, the unemployment scar is 'large'. The worker, who prefers continuation to separation at stage 1, concludes a SPC with $w_{A}>\omega_{A}$ to make his job more viable.

Formally, which variant of SPC applies for a worker of type $z \geq 0$ depends on the sign of the Lagrange multiplier associated with the incentive constraint. Specifically, the FOC (19) and (20) imply that $w_{A} \geq \omega_{A}$, if and only if $\gamma \geq 0$. The sign of $\gamma$ in turn depends on the weight the workers put on the scarring risk and the uninsurable income risk, whereas the importance of the income risk depends on the 'absolute prudence' of the utility function $u$. In order to develop the argument further, we assume that $u$ is a $C^{3}$ function.

Prudence. In the context of intertemporal expected utility maximization, the engagement of an investor in precautionary saving depends on the strength of his precautionary saving motive, which can be measured by the coefficient of absolute prudence $P(c)$ for which $P(c)=$ $-u^{\prime \prime \prime}(c) / u^{\prime \prime}(c)$. The precautionary motive implies $P(c)>0$ or, in view of $(\mathrm{A} 2), u^{\prime \prime \prime}(c)>0$. Moreover, the identity $P(c)=a(c)-a^{\prime}(c) / a(c)$ represents the relationship between absolute prudence $P(c)$ and the Arrow-Pratt measure of absolute risk-aversion $a(c)=-u^{\prime \prime}(c) / u^{\prime}(c)>0$. Obviously, the absolute risk aversion of $u$ is non-increasing, i.e. $a^{\prime}(c) \leq 0$, if and only if $P(c) \geq a(c)$ (Kimball 1990, Kimball and Weil 2003). 
The following lemma characterizes the dependence of the Lagrange multiplier $\gamma$ on the prudence of $u$ for a worker of type $z \in\left[0, z_{B_{3}}\right)$ who signs a third-best SPC $C_{A}$, where $R$ is the incentive compatible reservation productivity associated with $C_{A}$.

LEMMA 9. Using a second-order approximation to the state dependent marginal utilities of the dismissed worker $z$ about $\omega_{A}$, the FOC (19) - (21) imply

$$
\gamma(R)=\lambda G(R)(1-G(R)) u^{\prime \prime}\left(\omega_{A}\right) y\left[h(R)+P\left(\omega_{A}\right) y H(R)\right],
$$

where $H$ is the indefinite integral of the continuation rent $h$, i.e. $H^{\prime}(R)=h(R)$, such that $R_{m}$ minimizes $H(R)$ on $[\alpha, 1]$, where for the minimum value $H\left(R_{m}\right)>0$.

If $P=0$, the associated utility function $u$ is quadratic and vice versa. Considering equation (27), Figure 6 graphs the Lagrange multiplier for the quadratic case against the reservation productivity $R$. As (27) implies, $\gamma(R)$ has three zeros in this benchmark case, two of which are at the endpoints of the domain of the demand shock distribution and the third zero is at $R_{m} \in(\alpha, 1)$, for which $h\left(R_{m}\right)=0$ and therefore $\gamma\left(R_{m}\right)=0$. For the benchmark case, equation (27) together with (A2) point out that $\gamma(R)$ is strictly greater than zero on $\left(\alpha, R_{m}\right)$ and strictly smaller than zero on $\left(R_{m}, 1\right)$. Figure 7 illustrates a case with a positive coefficient of prudence.

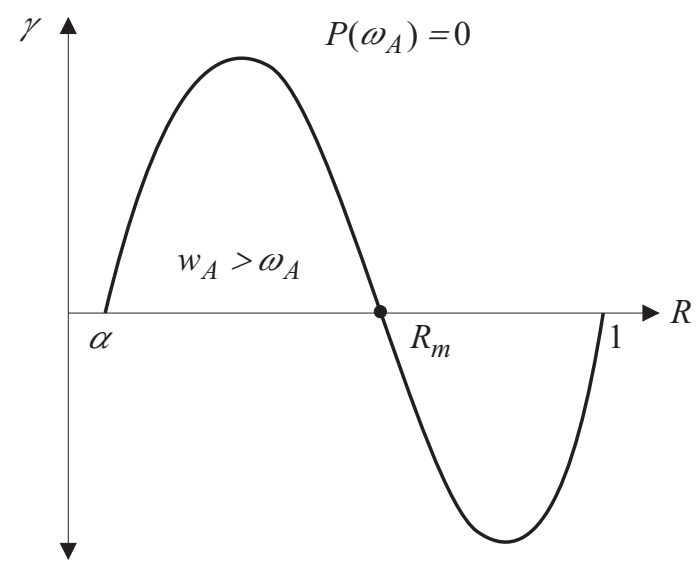

Fig. 6: Quadratic Utility with $R(0)<R_{0}=R_{m}$

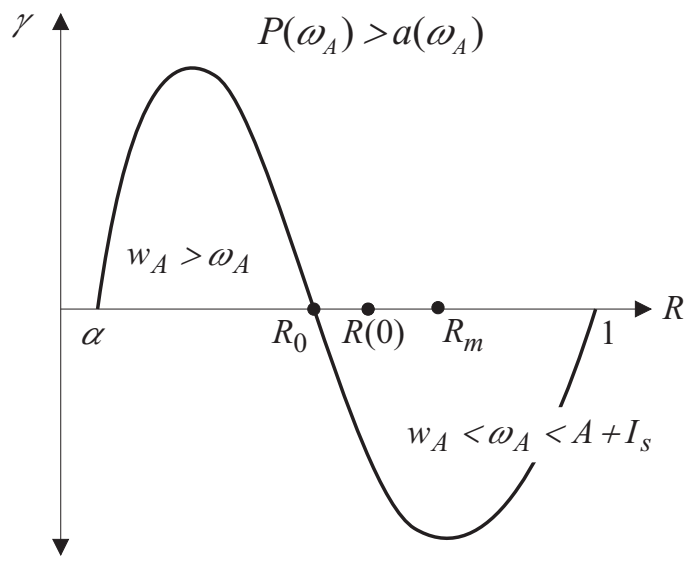

Fig. 7: Strictly decreasing absolute risk aversion with

$$
R_{0}<R(0)<R_{m}
$$

LEMMA 10. Let $P>0$ and assume

$$
h(\alpha)+P y H(\alpha)<0 .
$$

Then, considering equation (27), $\gamma(R)$ has a unique interior zero at a point $R_{0} \in\left(\alpha, R_{m}\right)$. Moreover, $\gamma(R)$ is strictly larger than zero on $\left(\alpha, R_{0}\right)$, while $\gamma(R)<0$ holds for all $R \in\left(R_{0}, R_{m}\right]$. 
Precautionary motive. The type-specific SPC of the marginal worker $z_{B_{3}}>0$ is associated with the incentive compatible reservation productivity $R\left(z_{B_{3}}\right)=\alpha$. To fix the endpoints of the interval of the third-best equilibrium reservation productivities $[\alpha, R(0)]$, it therefore remains to characterize $R(0)$, the reservation productivity of the neoclassical worker, where we already know from Lemma 8 (iii) and $z_{B_{3}}>0$ that $R(0)>\alpha$.

LEMMA 11. (i) Let the coefficient of absolute prudence at the neoclassical worker's contracted recession wage be non-negative, so that $P\left(\omega_{A}\right) \geq 0$, then $R(0)<R_{m}$. (ii) If for a worker $z \geq 0$, who signs a third-best SPC, $P\left(\omega_{A}\right) \geq 0$, then $z$ makes a SPC with an ex ante replacement rate which is larger than one, $A+y I_{S} \geq \max \left\{w_{A}, \omega_{A}\right\}$. (iii) Let the absolute risk aversion at the neoclassical worker's contracted recession wage be non-increasing, then the Lagrange multiplier $\gamma$ is non-positive, i.e. $P\left(\omega_{A}\right) \geq a\left(\omega_{A}\right)$ if and only if $\gamma(R(0)) \leq 0$.

Lemma 11 makes clear, that if the utility function $u$ exhibits non-negative absolute prudence, then, according to (i), neoclassical workers limit their exposure to the income risk, which they must bear, by choosing a SPC with labor hoarding, as $R(0)<R_{m}$. Remember, that $R_{m}$ is the choice of a neoclassical worker in the first-best and the second-best situation. Moreover, according to (ii), the precautionary motive induces workers with $z>0$, who opt for a SPC, to sign an agreement with an ex ante wage replacement rate strictly larger than one.

The Scar. Finally, according to Lemma 11 (iii), assuming a decreasing absolute risk aversion and the validity of (A4), $R_{0}<R(0)$, where $R_{0}$ is the unique interior zero of the Lagrange multiplier $\gamma(R)$ in $\left(\alpha, R_{m}\right)$ according to Lemma 10. Moreover, as $\gamma(R(0))<0$, the neoclassical worker favors in this case a third-best SPC with a steep income profile: $A+y I_{S}>\omega_{A}>$ $w_{A}$. The same is true for all worker types with a small scarring effect $z$, such that $R(z) \in\left(R_{0}\right.$, $R(0))$, while those workers, who fear a large scar, induce their employers to pick $R(z) \in(\alpha$, $R_{0}$ ) and conclude, for that reason, a SPC with a low recession wage: $A+y I_{S}>w_{A}>\omega_{A}$.

Why would a worker choose a high recession wage and, consequently, decide knowingly to risk his claim to a job? The answer, of course, must be, that the worker, given the terms of his SPC, prefers to be fired to a continuation of the job. And indeed, the FOC (23) together with the incentive constraint reveal, that all worker types $z \geq 0$, for whom $\gamma(R(z))<0$, prefer a separation at stage 1 of the sequence of events with the prospect of a high replacement income. 


\section{Summary}

The paper focuses on two labor markets, a spot market and a contract market. Firms are riskneutral; workers are risk-averse, fear the scarring effect of unemployment and choose between a contract and a spot market job. Contract jobs are confronted with a stochastic demand. If hit by a shock, the firm must decide whether to continue production or to terminate the job. Terminated workers look for another job on the spot market. Those workers, who cannot find a suitable follow-up job, become unemployed and suffer a worker-specific welfare loss from the scar inflicted by the job displacement. A variety of factors can be responsible for the scar. Being unemployed goes hand in hand with a loss of social status and social exclusion, brings about a deterioration of the human capital, lowers the subsequent earnings and increases the future incidence of unemployment.

The market system of the model is incomplete. There is no market, where workers could insure themselves against the income or the scarring risk of unemployment. CEP is the only means available to a worker to protect himself against the risks of a job displacement. It turns out that workers, who are confronted with the scarring effect of unemployment, strictly prefer CEP to a spot market job. Workers can choose between two contract forms, the guaranteed employment contract (GEC) and the severance pay contracts (SPC). With symmetric information, the terms of an efficient SPC include the agreed-upon wage, the severance pay, the private supplemental unemployment benefits (SUB) and a separation rule, which determines the reservation productivity at which the job will be terminated and firm and worker separate. A GEC fully insures a worker against both types of risk. SPC diversify the idiosyncratic part of the income risk, but provide only limited protection against the scarring risk. Which of the two contract forms a worker prefers depends on the weight of the expected scarring effect.

The comparative-static analysis of the contract market equilibrium under symmetric information reveals that the fraction of workers concluding a GEC increases with worker productivity, with a decreasing probability of a firm-specific demand shock, with a falling probability of finding a re-engagement, with a decreasing spot market wage and with decreasing public unemployment benefits.

With no ex post competition, the separation rule of an equilibrium SPC or GEC is ex post efficient. Indeed, if a contract stipulates production, even though the firm would incur a loss, the redundancy payment the risk-neutral firm would be ready to offer to the employee for his acceptance of a separation is strictly lower than the compensation payment, which the riskaverse worker would demand. Furthermore, if a SPC stipulates separation in a recession, such 
that the worker would have to face the threat of the unemployment scar, the pay cut that he is ready to offer to save his job is strictly less than the pay cut the firm would demand to continue the employment relation.

If workers cannot observe the firm-specific state of the demand during a downturn, the reservation productivity is not contractible, and the firm decides unilaterally on the termination of the job. Although the firm is risk-neutral, the efficient SPC are not incentive compatible, because SPC include a partial protection against the scarring effect, whereby a firm must hoard labor during a recession. Labor hoarding inflicts wage costs upon the firm, from which it can escape, if the output demand is not observed by the employee.

There are two sources for the inefficiency of the second-best equilibrium. First, the equilibrium fraction of workers concluding a GEC is too large, and second, those workers concluding a SPC bear income risk. A social planner will need three instruments to restore efficiency: A wage subsidy paid by the firm to the worker to smooth consumption, a firing tax borne by the firm to induce efficient separation, and an instrument to reimburse the firing tax and ensure efficient market entry.

Although workers have a strong 'intrinsic motive' to search for a (follow-up) job, asymmetric information about the re-employment of a dismissed worker makes it impossible to condition the contract on this status. Consequently, SUB are not contractible, if the re-employment status is not observable by the firm. The combination of both types of informational asymmetries on the state of the demand and on the re-employment of the dismissed worker further increases the equilibrium fraction of over-insured workers, who prefer to conclude the GEC.

The information asymmetries change the role that the contract wage paid in a recession and the severance pay play in comparison to the first-best situation. As the separation decision is not contractible, workers use the wage and the severance pay to push their employer to pick the most preferred from the set of ex post profit maximizing reservation productivities. A decreasing wage and/or an increasing severance pay will urge the firm to pick a lower reservation productivity, thereby reducing the scarring risk of unemployment.

With both asymmetries in place, workers, who sign a SPC, are not only confronted with the scarring risk of unemployment, but must also bear income risk. Precautionary workers exposed to the uninsurable income risk prefer a SPC with an ex ante replacement rate strictly larger than one. The unemployment scar on the other hand is responsible for the worker's selection of the contract wages for the good and the recession states. If the expected scar is small, the prospect of a high replacement income dominates the decision. The worker favors 
separation to continuation and signs a SPC with a high recession wage. If the unemployment scar is 'large', the worker prefers continuation to separation and concludes a SPC with a low recession wage to make his job more viable.

\section{References}

Akerlof, G.A.; H. Miyazaki (1980), The Implicit Contract Theory of Unemployment meets the Wage Bill Argument, Review of Economic Studies 47, 321-338.

Alvarez, F. and M. Veracierto (2001), Severance payments in an economy with frictions, Journal of Monetary Economics 47, 477-498.

Arnott, R.; A. Hosios; J. Stiglitz. (1988), Implicit Contracts, Labor Mobility, and Unemployment, American Economic Review 78, 1046-66.

Arulampalam, W.; P. Gregg; M. Gregory (2001a), Unemployment Scarring, The Economic Journal 111, F577-584.

Arulampalam, W. (2001b), Is unemployment really scarring? Effects of unemployment experiences on wages', The Economic Journal 111, F585-606.

Azariades, C. (1975), Implicit Contract and Underemployment Equilibria, Journal of Political Economy 83, 1183-1202.

Bertola, G. (2004), A Pure Theory of Job Security, Review of Economic Studies 71, 43-61.

Bryson, A.; L. Cappellari; C. Lucifora (2004), Do Job Security Guarantees Work?, Working Paper.

Burguet, R.; R. Caminal (2004), Does the market provide sufficient employment protection? CEPR Discussion Papers no. 4198, London.

Clark, A.; A. Oswald (1994). Unhappiness and Unemployment, Economic Journal, 104, 648-659.

Clark, A. (2001), Interactions In Labour Force Status, As Revealed By Proxy Utility Data, Annales d'Economie et de Statistique, 21-37.

Clark, A.; Y. Georgellis; P. Sanfey (2001), Scarring: the Psychological Impact of Past Unemployment, Economica, 68, pp.221-241.

Clark, A.; F. Postel-Vinay (2005), Job Security and Job Protection,

Deutscher Bundestag (1951), Entwurf eines Kündigungsschutzgesetzes, Drucksache Nr. 1/2090, Bonn.

DiTella, R.; R. MacCulloch; A. Oswald (2001), Preferences over Inflation and Unemployment: Evidence from Surveys of Happiness, American Economic Review 91, 335-341.

Fella, G. (2000), Efficiency wage and efficient redundancy pay, European Economic Review 44, 1473-1490.

Frey, B.; A. Stutzer (2002), What can Economists Learn from Happiness Research?, Journal of Economic Literature 40, 402-435.

Galdón-Sanchez, J.; M. Güell (2003), Dismissal conflicts and unemployment, European Economic Review 47, 323-335.

Goerke, L. (2002), On dismissal pay, Labour Economics 9, 497-512.

Gregory, M.; Jukes, R. (2001), Unemployment and Subsequent Earnings: Estimating Scarring Among British Men 1984-94, The Economic Journal 111, F607-625.

Grossman, S.J.; O. Hart (1981), Implicit Contracts, Moral Hazard, and Unemployment, American Economic Review 71, 301-307.

Grossman, S.J.; O. Hart (1983), Implicit Contracts und Asymmetric Information, Quarterly Journal of Economics 98, Suppl. 123-156.

Hansen, G.; A. Imrohoroglu (1992). The role of unemployment insurance in an economy with liquidity constraints and moral hazard, Journal of Political Economy 100, 118-142.

Hart, O. (1983), Optimal Labour Contracts under Asymmetric Information: An Introduction, Review of Economic Studies L, 3-35.

Holzmann, R.; K. Iyer; M. Vodopivec (2003), Severance Pay Programs around the World: Rationale, Status, and Reforms, Paper presented at the International Workshop on Severance Pay Reform: Toward Unemployment Savings and Retirement Accounts, Laxenberg/Vienna, November 2003.

Hopenhayn, H.; Rogerson, R. (1993), Job Turnover and Policy Evaluation: A General Equilibrium Analysis, in: Journal of Political Economy 101, S. 915-938.

Hurd, M. (1980), A Compensation Measure of the Cost of Unemployment to the Unemployed, Quarterly Journal of Economics 95, 225-243.

Jacobson, L.S., R.J. LaLonde, D.G. Sullivan (1993), Earnings Losses of Displaced Workers, American Economic Review 83, 685-709.

Kahn, Ch. (1985), Optimal Severance Pay with Incomplete Information, Journal of Political Economy 93, 435-51.

Kimball, M.S. (1990), Precautionary Saving in the Small and in the Large, Econometrica 58, 53-73. 
Kimball, M.S.; P. Weil (2003), Precautionary Saving and Consumption Smoothing Across Time and Possibilities, Working Paper.

Layard, R. (2005), Happiness: Lessons from a New Science, Penguin Press.

Ljungqvist, L. (2002), How Do Lay-Off Costs Affect Unemployment?, Economic Journal 112, 829-853.

Malcomson, J.M. (1999), Individual Employment Contracts, in: O. Ashenfelter, D. Card (eds.), Handbook of Labor Economics, Vol. 3, Amsterdam, 2292-2372.

Mortensen, D.; Ch. Pissarides (1994), Job Creation and Job Destruction in the Theory of Unemployment, Review of Economic Studies 61, 397-415.

Mortensen, D.; Ch. Pissarides (1999), Job Reallocation, Employment Fluctuations and Unemployment, in: J. Taylor, M. Woodford (eds.), Handbook of Macroeconomics, Vol. 1, Amsterdam, 1171-1228.

OECD (2004), Employment Outlook, Paris.

Oreopoulos, P.; M. Page; A.H. Stevens (2005), The Intergenerational Effects of Worker Displacement, NBER Working Paper W11587.

Parsons, D. (2002), Private 'Unemployment' Insurance: Asymmetric Information and Severance Pay Design, mimeo, George Washington University, Washington.

Pissarides, Ch. (2000), Equilibrium Unemployment Theory, 2. Edition, Cambridge.

Pissarides, Ch. (2001), Employment Protection, Labour Economics 8, 131-159.

Pissarides, Ch. (2002), Consumption and Savings with Unemployment Risk: Implications for Optimal Employment Contracts, Working Paper, LSE, London.

Rogerson, R.; M. Schindler (2002), The Welfare Cost of Worker Displacement, Journal of Monetary Economics 49, 1213-1234.

Rosen, S. (1985), Implicit Contracts: A Survey, Journal of Economic Literature 23, 1144-1175.

Ruhm, C.J. (1991), Are Workers Permanently Scarred by Job Displacement?, American Economic Review 81, 319-324.

Schmitz, P. (2004), Job protection laws and agency problems under asymmetric information, European Economic Review 48, 1027-1046.

Shapiro, C.; J. Stiglitz (1984), Equilibrium Unemployment as a Worker Discipline Device, in: American Economic Review 74, 433-444.

Stutzer, A,; R. Lalive (2004), The Role of Social Work Norms in Job Searching and Subjective Well-Being, Journal of the European Economic Association 2, 696-719.

Winkelmann, L.; R. Winkelmann (1998), Why Are the Unemployed So Unhappy? Evidence from Panel Data, Economica 65, 1-15. 


\section{Appendix}

\section{A1 Proof of Lemma 2}

Ad (i): Let worker $z$ be protected by an efficient employment contract $C=\left[w, C_{\lambda}\right]$. Moreover, assume that the job is hit by a shock. The substitution of the equations (9) into the utility functions (3) and (4) yields the state independent utilities $U^{+}\left(C_{\lambda}\right)=u(w)$ and $U^{-}\left(C_{\lambda}\right)=u(w)-$ $(1-p) y z$, conditional on whether production occurs or $C$ is terminated, respectively. As $U^{+}\left(C_{\lambda}\right) \geq U^{-}\left(C_{\lambda}\right)$, the worker always prefers production to separation, his preference being strict, if $z>0$. Ad (ii): The substitution of equations (9) into the profit functions (1) and (2) yields $J^{+}\left(C_{\lambda}(x)\right)=y x-w$ and $J^{-}\left(C_{\lambda}\right)=y I_{S}-w$. In case a shock $x$ occurs, the firm prefers production to separation, whenever $J^{+}\left(C_{\lambda}(x)\right) \geq J^{-}\left(C_{\lambda}\right)$. The inequality holds if and only if $y h(x) \geq 0$ and therefore with regard to (A3), if and only if $x \geq R_{m}$. Ad (iv): If the reservation productivity would not be unique we could find $R_{1}$ and $R_{2}$ with $R_{m} \geq R_{1}>R_{2}>\alpha, r\left(R_{1}\right)=$ $r\left(R_{2}\right)=1$ and $R_{1}>x>R_{2} \Rightarrow r(x)=0$, such that

$$
\begin{aligned}
J(C) & =(1-\lambda)(y-w)+\lambda \int_{\alpha}^{1}\left[r(x)(y x-w)+(1-r(x))\left[y I_{S}-w\right]\right] d G(x) \\
& =(1-\lambda)(y-w)+\lambda\left[y I_{S}-w\right]+\lambda y \int_{\alpha}^{1} r(x) h(x) d G(x) \\
& =(1-\lambda)(y-w)+\lambda\left[y I_{S}-w\right]+\lambda y\left[\int_{\alpha}^{R_{2}} r(x) h(x) d G(x)+\int_{R_{1}}^{1} r(x) h(x) d G(x)\right]
\end{aligned}
$$

Taking into account $r\left(R_{2}\right)=1, h\left(R_{2}\right)<0, g\left(R_{2}\right)>0$, differentiating $J(C)$ with respect to $R_{2}$ yields

$$
\frac{\partial J(C)}{\partial R_{2}}=\lambda y r\left(R_{2}\right) h\left(R_{2}\right) g\left(R_{2}\right)<0,
$$

contradicting the assumption that $C$ is efficient, because $\partial J(C) / \partial R_{2}<0$ implies that a reduction of $R_{2}>\alpha$ would not only increase the worker's utility, but also the profit of the firm. Q.E.D.

\section{A2 Concavity of the Wage Function (12) and Convexity of the Indifference Curves}

The Lagrangian function $\mathcal{L}(C, \delta)=U(C)+\delta J(C)$ is concave on the set of admissible contract terms, although in general neither the objective function $U(C)$ nor $\delta J(C)$ are. The concavity 
of the CMC and the convexity of the indifference curves are, therefore, sufficient, but not necessary, for the existence of an inner solution of the maximization problem.

1. Assume that the pdf $g$ is differentiable. For the first and second derivative of the wage function (12) with respect to $R$, we obtain, in view of $\mu^{\prime}(R)=-R g(R)$

$$
\begin{aligned}
\frac{d w}{d R} & =\lambda y(-R g(R))+\lambda g(R) y I_{S}, \quad \frac{d^{2} w}{d R^{2}}=-\lambda y\left[g^{\prime}(R) h(R)+g(R)\right] . \\
& =-\lambda g(R) y h(R)
\end{aligned}
$$

As $g(R)>0$ and $h(R) \leq 0$ for $R \in\left[\alpha, R_{m}\right], g^{\prime}(R) \leq 0$ is sufficient for the strict concavity of the wage function on $\left[\alpha, R_{m}\right)$.

2. It follows from (14) that

$$
\frac{d^{2} w}{d R^{2}}=\lambda(1-p) z \frac{g^{\prime}(R) u^{\prime}(w)-g(R) u^{\prime \prime}(w) \frac{d w}{d R}}{\left(u^{\prime}(w)\right)^{2}}
$$

$g^{\prime}(R) \geq 0$ is sufficient, but not necessary for $d^{2} w / d R^{2}>0$, given $d w / d R>0$ and $u^{\prime \prime}(w)<0$.

\section{A3 Proof of Lemma 3 and Proposition 1}

Proof of Lemma 3. From the tangential condition and the wage function (12), we obtain the reservation productivity $R$ as an implicit function $F$ of $z$, where $F(R, z) \equiv h(R)+z(1-p) / u^{\prime}\left(w_{A}(R)\right)=0$. The partial derivatives of $F$ with respect to $z$ and $R \in\left[\alpha, R_{m}\right)$ are: $F_{z}=(1-p) / u^{\prime}>0$ and $F_{R}=1-\left(z(1-p) u^{\prime \prime} /\left(u^{\prime}\right)^{2}\right)\left(d w_{A}(R) / d R\right)>0$. Therefore, we may use the Implicit Function Theorem, which yields the local existence of $R(z)$ and $d R / d z=-F_{z} / F_{R}<0$. Q.E.D.

Proof of Proposition 1. Given that $z_{B}$ would choose $R=\alpha$, the equilibrium price of the scarring risk, which the contract market offers, is $M P S=-\lambda g(\alpha) y h(\alpha)>0$, as follows from (13) and (A3). Moreover, we can derive from (14) the marginal rate of substitution for $z_{B}$ as $M R S=$ $\lambda g(\alpha)(1-p) y z_{B} / u^{\prime}\left(w_{B}\right)$. By inserting the MRS and the MPS into the tangential condition, we obtain (15).

\section{A4 Proof of Lemma 4 and Proposition 2}

Proof of Lemma 4. For the GEC wage $w_{B}$, we have $w_{B} \equiv y[1-\lambda(1-\mu)] \leq y I_{S}$ if and only if $h(1) \equiv 1-I_{S} \leq \lambda(1-\mu)$. Therefore, considering that $w(z)$ is a decreasing function of $z \geq 0$, 
see Lemma 3, the assumption of the lemma implies $w(z)=w_{B}<y I_{S}$ for all $z \geq z_{B}$. Moreover, in view of $R(0)=R_{m}$ and $h\left(R_{m}\right)=0$, the inequality $w(0)>y R(0)=y I_{S}$ is a special case of $w(z)>y R(z)-y h(R(z)) \lambda G(R(z))$, which is true for all $z \geq 0$, as will be shown below. Thus, a type $\hat{z} \in\left(0, z_{B}\right)$ exists, for which $w_{A}(\hat{z})=y I_{S}$ and $w_{B}<w_{A}(\hat{z})<w(0)$.

Next, we show that $w(z)>y R(z)-y h(R(z)) \lambda G(R(z))$ holds for all $z \geq 0$. By equation (12) and the definition of the continuation rent $h$, the strict inequality is true if and only if

$$
E y(R)+\lambda G(R) y I_{S}>(1-\lambda G(R)) y R+\lambda G(R) y I_{S},
$$

where we suppress the functional notation and the argument $z$. Inserting the definition of $E y(R)$, dividing through by $y$ and rearranging terms yields the conclusion that the above inequality holds if and only if $\Delta(R) \equiv[1-\lambda(1-\mu(R))]-(1-\lambda G(R)) R>0 . \Delta(R)$ is a strictly decreasing $C^{2}$ function, with $\Delta(\alpha)>0$ and $\Delta(1)=0$, as will be proved next. First, note that $\alpha<\mu(\alpha)=\mu<1, \mu(1)=0$ and $\lambda<1$, thus $\Delta(\alpha)=[1-\lambda(1-\mu)]-\alpha>0$ and $\Delta(1)=(1-\lambda)-$ $(1-\lambda)=0$. Moreover, in view of $\mu^{\prime}(R)=-R g(R)$, we obtain $\Delta^{\prime}(R)=-(1-\lambda G(R))<0$. Therefore $w(z)>y R(z)-y h(R(z)) \lambda G(R(z))$ for all $z \geq 0$. Q.E.D.

Proof of Proposition 2. Worker $z \geq 0$ is strictly better off with CEP than without it, if and only if

$$
U(C(z)) \equiv u(w(z))-\lambda G(R(z))(1-p) y z>p u(y v)+(1-p)[u(y b)-y z] \equiv V(z),
$$

where $R(z) \in\left[\alpha, R_{m}\right]$. Assume to the contrary that $U(C(z)) \leq V(z)$. In view of the risk aversion of the worker $z \geq 0$, the working hypothesis implies $0 \leq(1-\lambda G(R(z)))(1-p) y z<u(w(z)+$ $d(z))-u(w(z))$, where $d(z)=y I_{S}-w(z)$. The monotonicity of $u$ implies that $d(z)>0$, thus $0 \leq(1-\lambda G(R(z)))(1-p) y z<d(z) u^{\prime}(w(z))$. The contract $C(z)$ is efficient, therefore $(1-p) y z=$ $-y h(R(z)) u^{\prime}(w(z)), \quad$ so $\quad-y h(R(z))(1-\lambda G(R(z)))<d(z)$ from which $w(z)<y R(z)-$ $y h(R(z)) \lambda G(R(z))$, a contradiction to $w(z)>y R(z)-y h(R(z)) \lambda G(R(z))$, which must hold for all $z \geq 0$, as is shown in the proof of Lemma 4. Q.E.D.

\section{A5 Proof of Lemma 5.}

We use $w_{B}=y[1-\lambda(1-\mu)]$ to analyze the GEC, the equation (15) for the equilibrium share of workers, who conclude the GEC, and the wage equation (12) together with the tangential condition to analyze the SPC. 
1. The wage equation (12) and the tangential condition may be written as implicit functions of the two endogenous and the six exogenous variables to obtain

$$
\begin{aligned}
& J^{1}\left(w_{A}, R ; y, \lambda, p, v, b, z\right) \equiv y[1-\lambda(1-\mu(R))]+\lambda G(R) y I_{S}-w_{A}=0 \\
& J^{2}\left(w_{A}, R ; y, \lambda, p, v, b, z\right) \equiv h(R)+\frac{(1-p) z}{u^{\prime}\left(w_{A}\right)}=0
\end{aligned}
$$

We determine the signs of the partial derivatives of the above implicit functions with respect to (A1), (A2), (A3), $g(R)>0$ and $z>0$ and note that $h(R)<0$.

$$
\begin{array}{ll}
J_{w_{A}}^{1}=-1<0 & J_{w_{A}}^{2}=-\frac{(1-p) z u^{\prime \prime}\left(w_{A}\right)}{\left(u^{\prime}\left(w_{A}\right)\right)^{2}}>0 \\
J_{R}^{1}=-\lambda g(R) y h(R)>0 & J_{R}^{2}=1>0 \\
J_{y}^{1}=\frac{w_{A}}{y}>0 & J_{y}^{2}=0 \\
J_{\lambda}^{1}=-\frac{y-w_{A}}{\lambda}<0 & J_{\lambda}^{2}=0 \\
J_{p}^{1}=y \lambda G(R)(v-b)>0 & J_{p}^{2}=-(v-b)-\frac{z}{u^{\prime}\left(w_{A}\right)}<0 \\
J_{v}^{1}=y \lambda G(R) p>0 & J_{v}^{2}=-p<0 \\
J_{b}^{1}=y \lambda G(R)(1-p)>0 & J_{b}^{2}=-(1-p)<0 \\
J_{z}^{1}=0 & J_{z}^{2}=\frac{(1-p)}{u^{\prime}\left(w_{A}\right)}>0
\end{array} .
$$

The Jacobean determinant $J$ is negative, so that we may use the Implicit Function Theorem to determine the signs of the derivatives in Lemma 5 by use of Cramer's Rule. For example, we use the following notation: $d w_{A} / d \lambda=J_{w_{A} \lambda} / J<0$ and $d R / d \lambda=J_{R \lambda} / J>0$ etc.

$$
\begin{aligned}
& J \equiv\left|\begin{array}{lr}
J_{w_{A}}^{1} & J_{R}^{1} \\
J_{w_{A}}^{2} & J_{R}^{2}
\end{array}\right|=-\left[1+\lambda g(R) y h(R) \frac{(1-p) z u^{\prime \prime}\left(w_{A}\right)}{\left(u^{\prime}\left(w_{A}\right)\right)^{2}}\right]<0 \\
& J_{w_{A} y} \equiv\left|\begin{array}{lr}
-J_{y}^{1} & J_{R}^{1} \\
-J_{y}^{2} & J_{R}^{2}
\end{array}\right|=-\frac{w_{A}}{y}<0, \quad J_{R y} \equiv\left|\begin{array}{lr}
J_{w_{A}}^{1} & -J_{y}^{1} \\
J_{w_{A}}^{2} & -J_{y}^{2}
\end{array}\right|=-\frac{w_{A}}{y} \frac{(1-p) z u^{\prime \prime}\left(w_{A}\right)}{\left(u^{\prime}\left(w_{A}\right)\right)^{2}}>0 \\
& J_{w_{A} \lambda} \equiv\left(y-w_{A}\right) / \lambda>0, \quad J_{R \lambda} \equiv \frac{\left(y-w_{A}\right)}{\lambda} \frac{(1-p) z u^{\prime \prime}\left(w_{A}\right)}{\left(u^{\prime}\left(w_{A}\right)\right)^{2}}<0 \\
& J_{w_{A} p} \equiv-\lambda G(R) y(v-b)+\lambda g(R) y h(R)\left[(v-b)+\frac{z}{u^{\prime}\left(w_{A}\right)}\right]<0 \\
& J_{R p} \equiv-(v-b)\left[1+\lambda G(R)(1-p) y z \frac{u^{\prime \prime}\left(w_{A}\right)}{\left(u^{\prime}\left(w_{A}\right)\right)^{2}}\right]-\frac{z}{u^{\prime}\left(w_{A}\right)} \leq 0 \\
& J_{w_{A} v} \equiv-\lambda p y[G(R)-g(R) h(R)]<0
\end{aligned}
$$




$$
\begin{array}{ll}
J_{R v} \equiv-p\left[1+\lambda G(R)(1-p) y z \frac{u^{\prime \prime}\left(w_{A}\right)}{\left(u^{\prime}\left(w_{A}\right)\right)^{2}}\right] \leq 0 & \\
J_{w_{A} b}=J_{w_{A} v}(1-p) / p<0, & J_{R b}=J_{R v}(1-p) / p \leq 0 \\
J_{w_{A} z} \equiv-\lambda g(R)(1-p) y h(R) / u^{\prime}\left(w_{A}\right)>0, & J_{R z} \equiv(1-p) / u^{\prime}\left(w_{A}\right)>0 .
\end{array}
$$

Ad (i): $\quad d w_{A} / d y=J_{w_{A} y} / J>0, \quad d A / d y=d w_{A} / d y>0, \quad d R / d y=J_{R y} / J<0$, $d w_{B} / d y=[1-\lambda(1-\mu)]>0$ and $\frac{d z_{B}}{d y}=-\frac{h(\alpha) u^{\prime \prime}\left(w_{B}\right)}{(1-p)} \frac{d w_{B}}{d y}<0$.

Ad (ii): $\quad d w_{A} / d \lambda=J_{w_{A} \lambda} / J<0, \quad d A / d \lambda=d w_{A} / d \lambda<0, \quad d R / d \lambda=J_{R \lambda} / J>0$, $d w_{B} / d \lambda=-y(1-\mu)<0$ and $\frac{d z_{B}}{d \lambda}=-\frac{h(\alpha) u^{\prime \prime}\left(w_{B}\right)}{(1-p)} \frac{d w_{B}}{d \lambda}>0$.

Ad (iii): $\quad d w_{A} / d p=J_{w_{A} p} / J>0, \quad d w_{A} / d v=J_{w_{A} v} / J>0, \quad d w_{A} / d b=J_{w_{A} b} / J>0 \quad$ and $\frac{d z_{B}}{d p}=\frac{u^{\prime}\left(w_{B}\right)(v-\alpha)}{(1-p)^{2}}>0, \frac{d z_{B}}{d v}=\frac{u^{\prime}\left(w_{B}\right) p}{(1-p)}>0, \frac{d z_{B}}{d b}=u^{\prime}\left(w_{B}\right)>0$. That the demand for the risk-free GEC tends to zero as $p$ approaches one follows directly from (15). Ad (iv): $d w_{A} / d z=J_{w_{A} z} / J<0, d A / d z=d w_{A} / d z<0, d R / d z=J_{R y z} / J<0$.

\section{A6 Proof of Proposition 3}

Let $x \geq R(z)$. Below we prove that $u(w(z))>V(\bar{a}(R(z), 0, z)$. Thus, taking into account the monotonicity of $V(\bullet, 0, z)$ and the fact that $u(w(z))=V(\underline{a}(z), 0, z)$, the first part of the proposition follows.

The left hand side of $u(w(z))>V(\bar{a}(R(z), 0, z)$ denotes the certain ex post utility from carrying out $C(z)$, and the right hand side denotes the expected utility $V(\bar{a}(R(z), 0, z)$ from terminating $C(z)$ with the side payment $\bar{a}(R(z), z)$, where $V(\bar{a}(R(z), 0, z)=p u(\bar{a}(R(z), z)+y v)+$ $(1-p)[u(\bar{a}(R(z), z)+y b)-y z]$.

Assume $\bar{a}(R(z), z)$ would induce $z$ to accept the termination proposal of the firm, or, equivalently, let $u(w(z)) \leq V(\bar{a}(R(z), 0, z)$. As the worker is risk-averse, we obtain

$$
\begin{aligned}
u(w(z)) & <u(p(w(z)-y R(z)+y v)+(1-p)(w(z)-y R(z)+y b))-(1-p) y z, \\
& <u(w(z)-y h(R(z)))-(1-p) y z
\end{aligned}
$$


thus, $(1-p) y z<u(w(z)-y h(R(z)))-u(w(z))$, which is impossible, if $z=0$, as $h(R(0))=0$. In this case, therefore, the inequality of the proposition must hold. If $z>0$, then $h(R(z))<0$, and the tangential condition together with the risk aversion of the worker imply $u(w(z)-$ $y h(R(z)))-u(w(z))<-y h(R(z)) u^{\prime}(w(z))<(1-p) y z$, a contradiction to the working hypotheses. Consequently, the strict inequality of the proposition holds for all $z \geq 0$.

Let $x<R(z)$. From the above argument, we know that $u(\underline{w}(z))=u(w(z))-(1-p) y z>$ $u(w(z)+y h(R(z)))$, such that $\underline{w}(z))>w(z)+y h(R(z))=\bar{w}(R(z), z)$ taking account of the monotonicity of the utility function. From the last inequality, we obtain $\underline{\chi}(x) \geq \underline{\chi}(R(z))=$ $w(z)-\bar{w}(R(z), z)>w(z)-\underline{w}(z)=\bar{\chi}(z)$. Q.E.D.

\section{A7 Proof of Lemma 6, Lemma 7 and Proposition 4.}

Proof of Lemma 6. Under symmetric information, worker $z \in\left(0, z_{B}\right)$ concludes a SPC $C_{A}=$ $\left[w_{A}(z), R(z)\right]$ with $\alpha<R(z)<R_{m}$, where in view of (A3) $0>y h(R(z))=y\left[R(z)-I_{S}\right]$. Using the equations (9) and rearranging terms yields: $A(z)+(1-p) B=w_{A}(z)-y I_{S}$, which in turn implies $A(z)+(1-p) B-\left[w_{A}(z)-y R(z)\right]=y h(R(z))<0$, as $A(z)=w_{A}(z)-y v$. Q.E.D.

Proof of Lemma 7. Ad (ii): Let $\gamma<0$. Then, the FOC (19) - (22) imply $A+y v=A+B+y b<$ $w_{A}<\omega_{A}$, but from (23) $\lambda g(R)\left[u(A+y v)-u\left(\omega_{A}\right)-(1-p) y z\right]=-\not y>0$ thus $A+y v>\omega_{A}>$ $A+y v$, a contradiction, so $\gamma \geq 0$. From $\gamma>0, z=0$ and (19) - (22) we get $A+y v>w_{A}>$ $\omega_{A}$, but (23) implies $\omega_{A}>A+y v$, so $\gamma>0$ implies $z>0$. Finally let $\gamma=0$ and $z>0$. Then, assuming $R>\alpha$, from (19) - (22) we get $A+y v=w_{A}=\omega_{A}$, but (23) implies $A+y v>\omega_{A}$. Thus, $\gamma>0$, if $z>0$ and $R>\alpha$. Ad (iii): Follows from the FOC (21) and (22). Ad (iv): Follows from the FOC and from (ii). Ad (v): Below we prove that $R$ is a strictly decreasing function of $z$. The incentive constraint implies $A+(1-p) B-\left(\omega_{A}-y R\right)=(A+y v)-\left(\omega_{A}-\right.$ $y h(R))=0$, so $y h(R) \leq 0$ since $A+y v \geq \omega_{A}$. Thus $R(z) \in\left[\alpha, R_{m}\right]$. If $z=0$, we get $\gamma=0$, considering part (ii) of the lemma. For $\gamma=0, A+y v=\omega_{A}$ and thus $(A+y v)-\left(\omega_{A}-y h(R)\right)=$ $y h(R)=0$, so $R(0)=R_{m}$.

To prove that $R(z)$ is a strictly decreasing function of $z$, we develop the bordered $(n+k) \times$ $(n+k)=7 \times 7$ Hessian matrix for the Lagrangian function $\mathcal{L}\left(C_{A}, R, \delta, \gamma\right)=U\left(C_{A}, R\right)+$ $\delta J\left(C_{A}, R\right)+\gamma C\left(C_{A}, R\right)$, where $n=5$ and $k=2$. The determinant $H$ of the matrix has the sign 
of $(-1)^{n}=-1$ at an interior solution of the maximization problem (18). To develop $H$, we make use of the FOC and get

$$
H=-(1-\lambda)\left|\begin{array}{ccccccc}
u^{\prime \prime}\left(w_{A}\right) & 0 & 0 & 0 & 0 & 1-\lambda & 0 \\
0 & \lambda(1-G) u^{\prime \prime}\left(\omega_{A}\right) & 0 & 0 & -\gamma g /(1-G) & \lambda(1-G) & -1 \\
0 & 0 & \lambda G V_{A A} & \lambda G V_{A B} & \lambda g\left[V_{A}-\delta\right] & \lambda G & 1 \\
0 & 0 & \lambda G V_{B A} & \lambda G V_{B B} & \lambda g\left[V_{B}-(1-p) \delta\right] & \lambda G(1-p) & 1-p \\
0 & -\gamma g /(1-G) & \lambda g\left[V_{A}-\delta\right] & \lambda g\left[V_{B}-(1-p) \delta\right] & \mathcal{L}_{R R} & 0 & y \\
-1 & -\lambda(1-G) & -\lambda G & -\lambda G(1-p) & 0 & 0 & 0 \\
0 & -1 & 1 & 1-p & y & 0 & 0
\end{array}\right|
$$

where $g=g(R), G=G(R)$, and $V_{A}$ and $V_{A A}$, for example, denote the partial derivative and the second order partial derivative of $V(A, B, z)=p u(A+y v)+(1-p)[u(A+B+y b)-y z]$ with respect to the severance pay $A, V_{A}=\partial V(A, B, z) / \partial A>0$ and $V_{A A}=\partial^{2} V(A, B, z) / \partial A^{2}<0$. The partial derivatives of the FOC with respect to $z$ are zero with the exception of $\mathcal{L}_{R z}=$ $-\lambda g(R)(1-p) y<0$. Replacing the fifth column of $H$ with the negative of $\mathcal{L}_{R z}$ yields the determinant $H_{R z}$

$$
H_{R z}=-(1-\lambda)\left|\begin{array}{ccccccc}
u^{\prime \prime}\left(w_{A}\right) & 0 & 0 & 0 & 0 & 1-\lambda & 0 \\
0 & \lambda(1-G) u^{\prime \prime}\left(\omega_{A}\right) & 0 & 0 & 0 & \lambda(1-G) & -1 \\
0 & 0 & \lambda G V_{A A} & \lambda G V_{A B} & 0 & \lambda G & 1 \\
0 & 0 & \lambda G V_{B A} & \lambda G V_{B B} & 0 & \lambda G(1-p) & 1-p \\
0 & -\gamma g /(1-G) & \lambda g\left[V_{A}-\delta\right] & \lambda g\left[V_{B}-(1-p) \delta\right] & -\mathcal{L}_{R z} & 0 & y \\
-1 & -\lambda(1-G) & -\lambda G & -\lambda G(1-p) & 0 & 0 & 0 \\
0 & -1 & 1 & 1-p & 0 & 0 & 0
\end{array}\right|
$$

The evaluation of $H_{R z}$ yields

$$
H_{R z}=-\mathcal{L}_{R z} \lambda^{2}(1-\lambda) p(1-p) G u^{\prime \prime}(A+y v)\left[\lambda u^{\prime \prime}\left(w_{A}\right)+(1-\lambda)\left[(1-G) u^{\prime \prime}\left(\omega_{A}\right)+G u^{\prime \prime}(A+y v)\right]\right]>0 .
$$

Thus, there exists a strictly decreasing $C^{1}$ function $R(z), z \in\left(\alpha, R_{m}\right]$, for which $d R(z) / d z=$ $H_{R z} / H<0$. Q.E.D.

Proof of Proposition 4. Workers are risk-averse, so that the proposition follows directly from (15), (24) and $h(\alpha)<0$ :

$$
0<z_{B_{2}}=\frac{u\left(w_{B}-y h(\alpha)\right)-u\left(w_{B}\right)}{(1-p) y}<\frac{u^{\prime}\left(w_{B}\right)(-y h(\alpha))}{(1-p) y}=z_{B_{1}} \text {. Q.E.D. }
$$


A8 Proof of Lemma 8 and Proposition 5

Proof of Lemma 8. Ad (ii): Assume $\gamma \leq 0$, then the FOC (19) and (20) imply $\omega_{A} \geq w_{A}$. Moreover, from the FOC (23) $u\left(\omega_{A}\right) \leq V(A, 0, z) \leq V(A, 0,0)$, such that $A+y v>\omega_{A} \geq w_{A}$. Next assume $\gamma>0$, then (19) and (20) imply $\omega_{A}<w_{A}$, while from (21): $A+y v>w_{A}$, so that the proposition follows. Ad (iii): To prove that $R(z)$ is a strictly decreasing function of $z$, we develop the bordered $(n+k) \times(n+k)=6 \times 6$ Hessian matrix for the Lagrangian function $\mathcal{L}\left(C_{A}, R, \delta, \gamma\right)=U\left(C_{A}, R\right)+\delta J\left(C_{A}, R\right)+\gamma C\left(C_{A}, R\right)$, where $n=4$ and $k=2$. The determinant $H$ of the matrix has the sign of $(-1)^{n}=+1$ at an interior solution of the maximization problem (18) with unobservable $B=0$. To develop $H$, we make use of the FOC and obtain

$$
H=(1-\lambda)\left|\begin{array}{cccccc}
u^{\prime \prime}\left(w_{A}\right) & 0 & 0 & 0 & 1-\lambda & 0 \\
0 & \lambda(1-G) u^{\prime \prime}\left(\omega_{A}\right) & 0 & -\gamma g /(1-G) & \lambda(1-G) & -1 \\
0 & 0 & \lambda G V_{A A} & \lambda g\left[V_{A}-\delta\right] & \lambda G & 1 \\
0 & -\gamma g /(1-G) & \lambda g\left[V_{A}-\delta\right] & \mathcal{L}_{R R} & 0 & y \\
1 & \lambda(1-G) & \lambda G & 0 & 0 & 0 \\
0 & -1 & 1 & y & 0 & 0
\end{array}\right|,
$$

where $V_{A}=\partial V(A, 0, z) / \partial A>0$ and $V_{A A}=\partial^{2} V(A, 0, z) / \partial A^{2}<0$.

$$
H_{R z}=(1-\lambda)\left|\begin{array}{cccccc}
u^{\prime \prime}\left(w_{A}\right) & 0 & 0 & 0 & 1-\lambda & 0 \\
0 & \lambda(1-G) u^{\prime \prime}\left(\omega_{A}\right) & 0 & 0 & \lambda(1-G) & -1 \\
0 & 0 & \lambda G V_{A A} & 0 & \lambda G & 1 \\
0 & -\gamma g /(1-G) & \lambda g\left[V_{A}-\delta\right] & -\mathcal{L}_{R z} & 0 & y \\
1 & \lambda(1-G) & \lambda G & 0 & 0 & 0 \\
0 & -1 & 1 & y & 0 & 0
\end{array}\right|
$$

The partial derivatives of the FOC with respect to $z$ are zero with the exception of $\mathcal{L}_{R z}=-\lambda g(R)(1-p) y<0$. Replacing the fourth column of $H$ with the negative of the partial derivatives of the FOC with respect to $z$ yields the above determinant $H_{R z}$. The evaluation of $H_{R z}$ gives

$$
H_{R z}=-\lambda(1-\lambda) \mathcal{L}_{R z}\left[\lambda u^{\prime \prime}\left(w_{A}\right)+(1-\lambda)\left[(1-G) u^{\prime \prime}\left(\omega_{A}\right)+G V_{A A}\right]\right]<0 .
$$

Thus, $R$ is a strictly decreasing function of $z$, as $d R(z) / d z=H_{R z} / H<0$. Q.E.D.

Proof of Proposition 5. Denote the worker type who is indifferent between the GEC and the type-specific SPC with $\hat{z}$. The type-specific SPC includes the wages $w_{A}=\omega_{A}=w_{B}$ and the severance pay $A=\omega_{A}-y \alpha$. Under these contract terms, $\hat{z}$ is indeed indifferent between the 
two contract forms, while the firm employing $\hat{z}$ would choose the reservation productivity $R=\alpha$. Inserting the terms of the SPC and $R=\alpha$ into the constraints of (18), we find that both are fulfilled as strict equalities. In view of $\gamma=\lambda(1-G(R))\left[u^{\prime}\left(\omega_{A}\right)-u^{\prime}\left(w_{A}\right)\right]=0$ and the FOC (23), it follows from

$$
\mathcal{L}_{R}(\hat{z}) \equiv-\lambda g(\alpha)\left[u\left(w_{B}\right)-p u\left(w_{B}+y(v-\alpha)\right)-(1-p) u\left(w_{B}+y(b-\alpha)\right)+(1-p) y \hat{z}\right]=0
$$

that the marginal worker is characterized by $z_{B_{3}}=\max \{0, \hat{z}\}$. The risk aversion of the worker together with $h(\alpha)<0$ and $\mathcal{L}_{R}\left(z_{B_{3}}\right) \leq 0$ imply $(1-p) y z_{B_{3}}<u\left(w_{B}-y h(\alpha)\right)-u\left(w_{B}\right)=(1-p) y z_{B_{2}}$. That $b \geq \alpha$ is sufficient for $z_{B_{3}}>0$ follows from (a1) and assumptions (A1) and (A2). Q.E.D.

\section{A9 Proof of Lemma 9, Lemma 10 and Lemma 11}

Proof of Lemma 9. The FOC (19) and (20) imply

$$
\gamma=\lambda(1-G)\left[u^{\prime}\left(\omega_{A}\right)-u^{\prime}\left(w_{A}\right)\right]
$$

where $G=G(R)$. Insert (a2) into the FOC (21) and take account of the incentive constraint to get

$$
u^{\prime}\left(\omega_{A}\right)-u^{\prime}\left(w_{A}\right)=-G\left[p u^{\prime}\left(\omega_{A}+y(v-R)\right)+(1-p) u^{\prime}\left(\omega_{A}+y(b-R)\right)-u^{\prime}\left(\omega_{A}\right)\right]
$$

A second order approximation to $u^{\prime}\left(\omega_{A}+y(v-R)\right)$ and $u^{\prime}\left(\omega_{A}+y(b-R)\right)$ about $\omega_{A}$ gives

$$
\begin{aligned}
p u^{\prime}\left(\omega_{A}+y(v-R)\right)+(1-p) u^{\prime}\left(\omega_{A}+y(b-R)\right)-u^{\prime}\left(\omega_{A}\right) & \approx-u^{\prime \prime}\left(\omega_{A}\right) y h(R)+u^{\prime \prime \prime}\left(\omega_{A}\right) y^{2} H(R) \\
& \approx-u^{\prime \prime}\left(\omega_{A}\right) y\left[h(R)+P\left(\omega_{A}\right) y H(R)\right]
\end{aligned}
$$

where $h(R)=R-p v-(1-p) b \quad$ and $\quad H(R)=\frac{1}{2}\left[p(v-R)^{2}+(1-p)(b-R)^{2}\right], \quad$ such that $H^{\prime}(R)=h(R)$. Thus, $H^{\prime}\left(R_{m}\right)=0$ and $H\left(R_{m}\right)>0$. Finally, insert (a4) into (a3) and the result into (a2) to get equation (27). Q.E.D.

Proof of Lemma 10. The function $F$ with $F(R)=h(R)+P y H(R)$ and $P>0$ is a polynomial of degree two, with first derivative $F^{\prime}(R)=1+P y h(R)$ and second derivative $F^{\prime \prime}(R)=P y>0$. Let $\hat{R}$ be the real number, for which $F^{\prime}(\hat{R})=0 . \hat{R}$ is the minimum point of the strictly convex function $F$. Note that $F^{\prime}(R) \geq 1$ for all $R \geq R_{m}$. Thus, $\hat{R}<R_{m}$. There are two cases to distinguish. If $\hat{R} \leq \alpha$, then $F$ is increasing on $\left[\alpha, R_{m}\right]$, such that $F\left(R_{m}\right)=\operatorname{PyH}\left(R_{m}\right)>0$ is a boundary maximum and $F(\alpha)=h(\alpha)+P y H(\alpha)<0$ is a boundary minimum of $F$ in $\left[\alpha, R_{m}\right]$, 
in view of (A4). If $\hat{R} \in\left(\alpha, R_{m}\right), F$ has an interior minimum at $\hat{R}$ in $\left(\alpha, R_{m}\right)$, such that $F(\hat{R})<F(\alpha)<0$. In both cases, the intermediate value theorem implies that $F$ has a unique zero at a point $R_{0}$ between $\alpha$ and $R_{m}$ in the first and between $\hat{R}$ and $R_{m}$ in the second case, where $\gamma\left(R_{0}\right)=\lambda G\left(R_{0}\right)\left(1-G\left(R_{0}\right)\right) u^{\prime \prime}\left(\omega_{A}\right) y F\left(R_{0}\right)=0$. Consequently, we get for the sign of $F$ and the Lagrange multiplier $\gamma(R)$ that $F(R)<0$ and, therefore, $\gamma(R)>0$ for all $R \in\left[\alpha, R_{0}\right)$, while $F(R)>0$ and $\gamma(R)<0$, for $R \in\left(R_{0}, R_{m}\right.$ ]. Q.E.D.

Proof of Lemma 11. The FOC (23) and the incentive constraint imply

$$
y \gamma=\lambda g\left[u\left(\omega_{A}\right)-p u\left(\omega_{A}+y(v-R)\right)-(1-p) u\left(\omega_{A}+y(b-R)\right)+(1-p) y z\right],
$$

where $g=g(R)$. From a second-order approximation to $u\left(\omega_{A}+y(v-R)\right)$ and $u\left(\omega_{A}+y(b-R)\right)$ about $\omega_{A}$, we get

$$
\begin{aligned}
u\left(\omega_{A}\right)-p u\left(\omega_{A}+y(v-R)\right)-(1-p) u\left(\omega_{A}+y(b-R)\right) & \approx y h(R) u^{\prime}\left(\omega_{A}\right)-u^{\prime \prime}\left(\omega_{A}\right) y^{2} H(R) \\
& \approx u^{\prime}\left(\omega_{A}\right)\left[y h(R)+a\left(\omega_{A}\right) y^{2} H(R)\right]
\end{aligned}
$$

Insert (a6) into (a5) to get

$$
\gamma(R)=\lambda g(R) u^{\prime}\left(\omega_{A}\right)\left[h(R)+a\left(\omega_{A}\right) y H(R)+\frac{(1-p) z}{u^{\prime}\left(\omega_{A}\right)}\right] .
$$

Ad (i): Let $P\left(\omega_{A}\right) \geq 0$ and suppose $R(0) \geq R_{m}$. Then, equation (27) implies $\gamma(R(0)) \leq 0$, such that the expression in square brackets of equation (a7) must be non-positive. But this is only possible, if $h(R(0))<0=h\left(R_{m}\right)$ implying $R(0)<R_{m}$, which is a contradiction to our assumption. Ad (ii): From the incentive constraint, we get $A+y I_{S}=\omega_{A}-y R+y I_{S}=\omega_{A}-$ $y h(R)$. As $R \leq R(0)<R_{m}$, it follows that $A+y I_{S}=\omega_{A}-y h(R)>\omega_{A}$. Two cases can be distinguished. If $\gamma \leq 0$, then we obtain from the FOC (19) and (20) that $w_{A} \leq \omega_{A}$ and the conclusion follows. If $\gamma>0$, then from the FOC (19) and (20) $w_{A}>\omega_{A}$, whereas the FOC (21) implies $p u^{\prime}(A+y v)+(1-p) u^{\prime}(A+y b)<u^{\prime}\left(w_{A}\right)$, such that in view of the non-negative prudence, $u^{\prime}\left(A+y I_{S}\right)<u^{\prime}\left(w_{A}\right)$, from which $A+y I_{S}>w_{A}$, such that the statement follows. Ad (iii): “ $\Rightarrow$ " Let $P\left(\omega_{A}\right) \geq a\left(\omega_{A}\right)>0$ and assume $\gamma(R(0))>0$. Then, considering $u^{\prime}\left(\omega_{A}\right)>0>u^{\prime \prime}\left(\omega_{A}\right)$, the expression in square brackets in equation (27) is strictly smaller than zero. Therefore, taking account of $P\left(\omega_{A}\right) \geq a\left(\omega_{A}\right)>0$ and $z=0$, the bracketed expression of (a7) is also smaller than zero, such that $\gamma(R(0))<0$, contradicting the working hypotheses. " $\Leftarrow$ " If $\gamma(R(0)) \leq 0$, then the expression in the square brackets of equation (27) is non-negative, while the corresponding expression of equation (a7) is non-positive: $h(R(0))+P\left(\omega_{A}\right) y H(R(0)) \geq 0 \geq$ $h(R(0))+a\left(\omega_{A}\right) y H(R(0))$, as $z=0$. The inequalities together with $y H(R(0))>0$ imply the proposition. Q.E.D. 